\title{
Analysis of primary bleed and feed strategies for selected SBLOCA sequences in a German Konvoi PWR using ASTEC V2.0
}

\author{
Ignacio Gómez-García-Toraño ${ }^{a}$, Víctor-Hugo Sánchez-Espinoza ${ }^{\mathrm{a}, *}$, Robert Stieglitz ${ }^{\mathrm{a}}$, César Queral ${ }^{\mathrm{b}}$

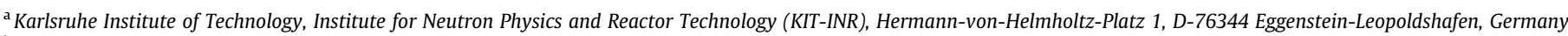 \\ ${ }^{\mathrm{b}}$ Universidad Politécnica de Madrid (UPM), Spain
}

\section{A R T I C L E I N F O}

\section{Article history:}

Received 11 April 2017

Received in revised form 24 July 2017

Accepted 4 August 2017

\section{Keywords:}

ASTEC

German Konvoi PWR

Small break LOCA

Station blackout

Severe accident management

Primary bleed and feed

\begin{abstract}
A B S T R A C T
The severe accidents at Fukushima have shown that a further development of Severe Accident Management Guidelines (SAMGs) is necessary. Within this work, the severe accident code ASTEC V2.0 is used to assess the impact of selected SAM measures on the in-vessel progression of Small Break (SBLOCA) scenarios in a generic German Konvoi PWR.

The progression of reference SBLOCA sequences with and without Station Blackout (SBO) is firstly analyzed. Calculations show that melting and vessel failure can be delayed if the secondary side is filled before the plant is struck by the SBO. Based on these results, a systematic evaluation of primary side depressurization and core reflooding as primary SAM measures is carried out. Simulations yield the following results:
\end{abstract}

- Primary Side Depressurization must be initiated before the Core Exit Temperature $($ CET $)>400^{\circ} \mathrm{C}$ or, if not possible, with a maximum delay of 20 min to delay core melting and vessel failure.

- Core reflooding must be launched immediately after CET $>650^{\circ} \mathrm{C}$ with at least $7.50-20 \mathrm{~kg} / \mathrm{s}$ in order to mitigate the accident without major core damage.

- If an external injection is used for such aim, the deployment order of a medium-high pressure head ( $>20$ bars) mobile pump must be issued $1 \mathrm{~h}$ after the entrance in SBO.

- Vessel failure cannot be prevented if more than 20 corium tons are present in the lower plenum for more than $1 \mathrm{~h}$ regardless of the injection rate.

The performed investigations clarify ASTEC V2.0 capabilities to describe the in-vessel progression of a severe accident in PWRs and contribute to extend the technical basis for the further improvement of SAMGs in German Konvoi PWR.

(c) 2017 Elsevier Ltd. All rights reserved.

\section{Introduction}

Beyond design basis accidents in nuclear power plants (NPPs) are a major concern due to the hazardous consequences that they may inflict. In order to control those, NPPs envisage the existence

\footnotetext{
Abbreviations: ACCUs, accumulators; AM, accident management; CET, core exit temperature; DGs, diesel generators; ECCS, emergency core cooling system; EFWS, emergency feed water system; FOM, figure of merit; HPIS, high pressure injection system; LP, lower plenum; LPIS, low pressure injection system; MCP, main coolant pump; NPP, nuclear power plant; PORV, pilot operated relief valve; PSD, primary side depressurization; RCPS, reactor control protection system; RCS, reactor coolant system; RMFR, reflooding mass flow rate; RPV, reactor pressure vessel; SAM, severe accident management; SAMGs, severe accident management guidelines; SBLOCA, small break LOCA; SBO, station blackout; SG, steam generator; SV, safety valve.

* Corresponding author.

E-mail address: victor.sanchez@kit.edu (V.-H. Sánchez-Espinoza).
}

of Accident Management (AM) programs, which aim at preventing and mitigating core damage, maintaining containment integrity and minimizing off-site releases (IAEA, 2004). The AM measures aiming at the first goal are tagged as preventive, whereas those pointing at the latter three are tagged as mitigative and often referred to as Severe Accident Management (SAM) measures.

The last decades have seen a worldwide improvement of SAM measures (EPRI, 2012, 1993; European Commission, 2000), especially after the severe accident occurred at the Unit 2 of Three-Miles-Island (Broughton et al., 1989). In turn, this progress has allowed the creation of plant-specific Severe Accident Management Guidelines (SAMGs) in accordance to the requirements of the national regulatory bodies, generally in compliance with the IAEA $(2009,2004)$ and WENRA (2014, 2007) safety standards. 
However, the accidents at the Units 1,2 and 3 of the Fukushima NPP have revealed that a further enhancement of SAM measures is necessary (NEA-OECD, 2013). As a result, significant changes to plant coping capabilities have been made to water cooled NPPs worldwide (Hermsmeyer et al., 2014; Lutz and Prior, 2016). In Germany, these changes have been included in an Action Plan for the implementation of measures after Fukushima (BMUB, 2016, 2014 ,2012), elaborated by the Reactor Safety Commission (RSK) upon request from the Federal Ministry for the Environment, Nature Conservation and Nuclear Safety (BMUB). These recommendations have concerned, for example, the implementation of plant specific SAMGs, recently fulfilled (Braun et al., 2014), and the optimization of accident measures and the review of injection possibilities under Station Blackout conditions.

For the elaboration of SAMGs, a broad number of deterministic analyses considering the risk-relevant sequences of the NPP under consideration must be produced using validated severe accident simulations tools, which are at the state-of-the-art in terms of modelling (Bunt et al., 2015; Klein-Heßling et al., 2014). Hence, the validation and improvement of severe accident codes is pursued worldwide through dedicated research programs (European Commission, 2017; Jacquemain et al., 2015; Miassoedov et al., 2015; Van Dorsselaere et al., 2015).

The European severe accident ASTEC code, jointly developed by Institut de Radioprotection et de Sûreté Nucléaire (IRSN) and Gesellschaft für Anlagen und Reaktorsicherheit (GRS), can simulate complete severe accident sequences (Chatelard et al., 2014). Furthermore, within the EU CESAM project (GRS, 2017), ASTEC capabilities are being improved (new modelling features, extended validation, enhancement of numerics) in order to support the choice of SAM strategies for different types of water cooled NPPs (Chatelard et al., 2016).

Within this work, the ASTEC V2.0 (rev3) version is applied to assess the impact of selected SAM measures (e.g. primary side depressurization, core reflooding) on the in-vessel progression of selected SBLOCA sequences in a generic German Konvoi PWR, continuing the work initiated in (Gómez-García-Toraño et al., 2017). SBLOCAs in the main coolant line have been selected due to its high significance for the risk of core damage in such plants (GRS, 2002). Analyses consider the aforementioned recommendations of the RSK after the Fukushima accidents.

First of all, a brief description of the ASTEC V2.0 numerical tool and about generic model of a Konvoi PWR (e.g. geometry, safety systems and automatisms) is presented in Section 2. The Section 3 goes on to explain the evolution of the reference sequences without operator actions. These consider the availability of all active systems until the plant is struck by an SBO at an uncertain time of the accident. Based on these reference sequences, the Section 4 investigates the impact of a delayed Primary Side Depressurization and of a delayed water injection into the primary circuit by means of hypothetical mobile pumps. Finally, Section 5 encompasses the main conclusions of this work and offers an outlook for the continuation of these investigations in the short and long term.

\section{Numerical tool and PWR plant model}

\subsection{The European reference code ASTEC}

The integral severe accident code ASTEC V2.0 (Chatelard et al., 2014 ) is the European reference tool for the analysis of severe accidents in LWR. The code is able to simulate complete severe accident sequences. The main applications areas are source term determination, Probability Safety Assessment and SAM studies. The structure of ASTEC is modular, each of its modules considering a particular domain of the reactor or a set of physical phenomena.
For the description of the in-vessel SA-phenomena, the modules of interest are the CESAR and ICARE modules. In ASTEC V2.0, CESAR simulates the thermal-hydraulics of the primary and secondary circuit, as well as in the Reactor Pressure Vessel (RPV) up to the beginning of core degradation. From this moment on, CESAR calculates the thermal hydraulics throughout the primary and secondary circuit, whereas ICARE overtakes the thermal-hydraulics within the vessel as soon as the core is uncovered. Both modules solve the thermal-hydraulics in one dimension by making use of five-equation approach.

\subsection{Generic PWR Konvoi plant model with ASTEC V2.0}

The reference plant is the four loop German Konvoi PWR (Ludwig, 2007; Siemens, 1991; Ziegler and Allelein, 2013). The ASTEC V2.0 model of a generic German Konvoi PWR used in the current work has been derived from a more detailed one used by GRS in previous studies (Nowack et al., 2011; Reinke et al., 2013). The geometry of the reactor domains, the physical phenomena considered during the in-vessel phase and the most relevant safety systems are identical to the ones described in (Gómez-Gar cía-Toraño et al., 2017).

A simplified sketch of the primary and secondary circuits (together with the relevant safety systems for this work) is depicted in Fig. 1. The four loop PWR is represented by two loops: the loop B (containing the pressurizer) and the loop A (containing the other three loops). The RPV is radially divided in eight channels: the downcomer (connected to the cold leg collector), the bypass and the six core channels (connected to the upper plenum). The bottom of the active core height corresponds to the elevation $\mathrm{z}=0 \mathrm{~m}$; the top corresponds to the elevation $\mathrm{z}=3.90 \mathrm{~m}$; the bottom of the lower head corresponds to the elevation $z=-3 \mathrm{~m}$.

The pressurizer is equipped with a Pilot Operated Relief Valve (PORV), which discharges into the pressurizer relief tank for system pressures above 166 bar, and with two Safety Valves (SV1 and SV2), discharging into the same tank for system pressures above 170 bar and 176 bar. All valves can be opened upon request if DC power is available.

In addition to the representation of the primary and secondary circuits, the following automatic actions and safety systems are also included in the ASTEC plant model:

- SCRAM initiated by the Reactor Control Protection System (RCPS) when the Reactor Coolant System (RCS) pressure falls below 132 bar or when the containment overpressure exceeds 30 mbar.

- Following SCRAM, the RCPS closes the steam admission to the turbine and shuts down the main feedwater pumps into the Steam Generators (SG). If the two conditions are fulfilled, the reactor is cooled down at a rate of $100 \mathrm{~K} / \mathrm{h}$ through the SGs.

- The Emergency Core Cooling System (ECCS) is activated when two of the following three conditions are fulfilled: containment overpressure above 30 mbar, RCS pressure below 110 bar or pressurizer liquid level below $2.30 \mathrm{~m}$.

- Following the ECCS criterion, the Main Coolant Pump (MCPs) are coasted down and the pressure regulation in the pressurizer is switched off.

The Emergency Feedwater System (EFWS) is activated when the liquid level of one SG falls below $4.50 \mathrm{~m}$ (relative to the bottom of the riser region), and regulates liquid level in the riser region to keep covered the U-tubes. The Extra Borating System is activated when the pressurizer water level falls below $2.30 \mathrm{~m}$ (relative to the bottom of the pressurizer), and injects $8 \mathrm{~kg} / \mathrm{s}(2 \mathrm{~kg} / \mathrm{s}$ per train) in the cold legs of the RCS. The water is aspired from specific borated tanks with a capacity of $18 \mathrm{~m}^{3}$. 


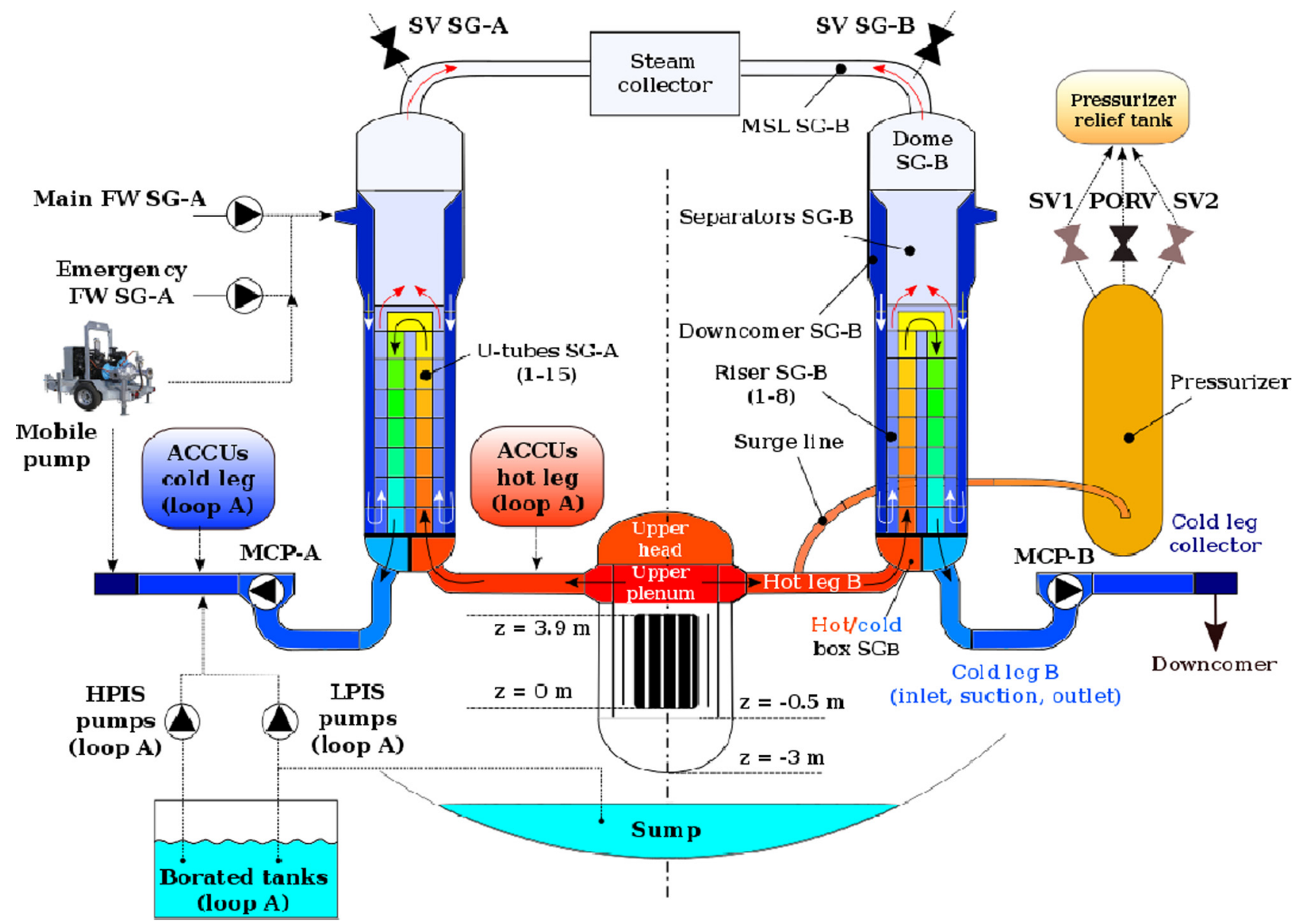

Fig. 1. Sketch of the Primary and Secondary circuit modelling for a generic German Konvoi PWR by ASTEC V2.0 (Gómez-García-Toraño et al., 2017).

The ECCS consists of passive accumulators (ACCUs) and the active High and Low Pressure Injections Systems (HPIS and LPIS). The ACCUs discharge at an initial pressure of 25 bar into the hot and cold legs of the RCS. Each train of the HPIS injects up to $75 \mathrm{~kg} / \mathrm{s}$ below 110 bar, whereas each train of the LPIS injects up to $150 \mathrm{~kg} / \mathrm{s}$ below 12 bar. Each train of the HPIS and the LPIS takes water from a different borated water tank (with a capacity of $480 \mathrm{~m}^{3}$ ) and injects it into the cold leg collector. Trains injecting into the same loop take water from the same tank. The existence of mobile pumps injecting into the cold leg collector of the RCS has been assumed. The name of the mobile pumps, their pressure head and their nominal flow rate are encompassed in Table 1.

\section{Analysis of SBLOCA-sequences without SAM}

The reference SBLOCA sequence paper postulates a $10 \mathrm{~cm}^{2}$ break in the cold leg of the pressurizer loop (see Fig. 1) at $0.0 \mathrm{~h}$. The following assumptions are made:

Table 1

Main features of the mobile equipment injecting into the primary circuit.

\begin{tabular}{lll}
\hline Name & Head (bar) & Flow rate $(\mathrm{kg} / \mathrm{s})$ \\
\hline M651h & 50 & 22 \\
M100h & 45 & 41 \\
XH100 & 18 & 80 \\
HH125 & 10 & 45 \\
AE18G & 7 & 130 \\
\hline
\end{tabular}

- Failure of the automatic $100 \mathrm{~K} / \mathrm{h}$ cooldown procedure through the SGs.

- Availability of 3 out of 4 trains of the HPIS and the LPIS. The fourth is assumed to be under maintenance.

- Failure of sump recirculation mode.

- No Accident Management measures.

In a first step, Section 3.1 studies the behaviour of the reactor considering that there is an unlimited AC power supply. Then, Section 3.2 postulates that the plant enters in Station Blackout at a different times after SCRAM.

\subsection{Reference SBLOCA sequence with unlimited AC power}

The SBLOCA sequence analysed in this section, identified as (SBLOCA-) Ref, assumes the availability of AC power supply during the whole transient. Hence, it involves all safety systems enumerated in Section 2.2, except the ones introduced in Section 3. For better understanding, Fig. 2 provides the reader with a sketch of one primary and secondary loop at the time of the initiating event as well as the safety systems assumed to work during the accident.

The evolution of pressures, void fractions, temperatures, heat transfer rates at relevant plant locations and the mass flow rates injected by key safety systems and exiting the circuit through the break can be found in Figs. 3-4. The coloured vertical lines mark occurrence times of major events in the simulation. The summary of events occurring in the simulation relative to the break opening is shown in Table 2. 


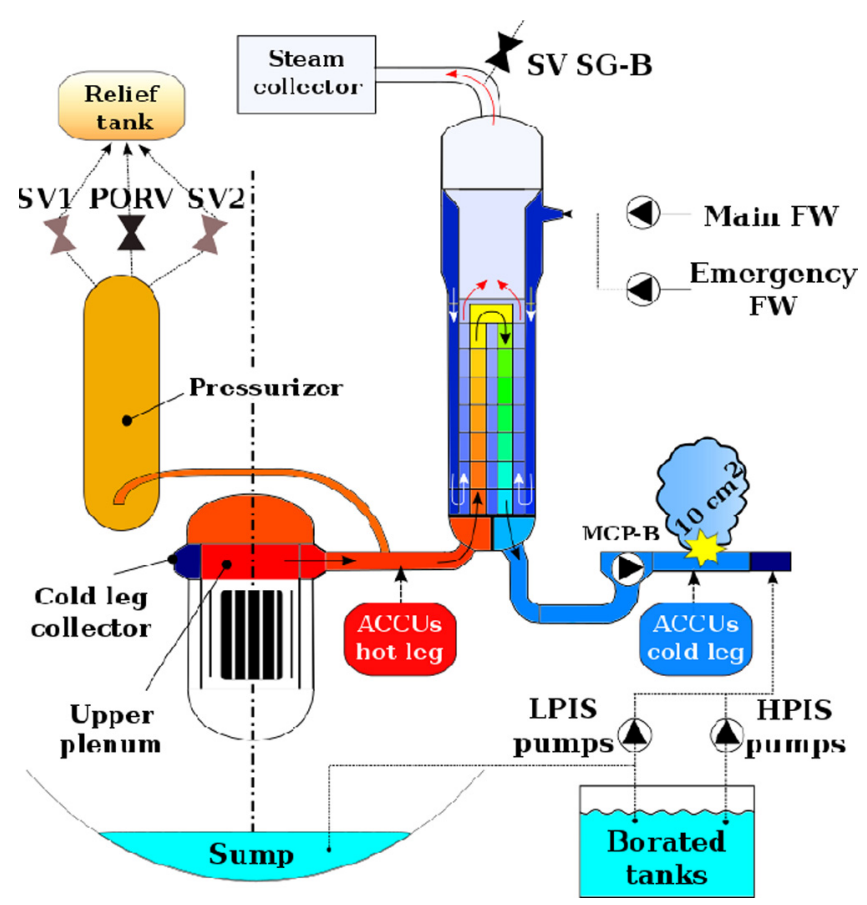

Fig. 2. Sketch of the primary loop containing the pressurizer and its associated secondary loop, together with the plant safety systems involved in Ref-SBLOCA. Breach located in the cold leg of pressurizer loop, just before the entrance to the cold leg collector.

After the break opening, the containment pressure rapidly increases by 30 mbar, leading to SCRAM. Then, the RCPS issues the signal of turbine trip, triggering the set of automatic actions described in Section 2.2. Meanwhile, the pressurizer reaches saturation and its liquid level decreases below $2.28 \mathrm{~m}$, leading to the fulfillment of ECCS criteria and other related actions (see Section 2.2).

The performance of the HPIS is limited $(50-70 \mathrm{~kg} / \mathrm{s}$ ) during the first minutes, because the RCS pressure is still high (100 bar), and does not manage to replace the loss of inventory through the break (Fig. 3-b). Consequently, the pressure continues falling down to 75 bar. From that point in time (and up to the depletion of the borated water tanks at about $4 \mathrm{~h}$ ), the HPIS is able to compensate the loss of water inventory through the break $(110 \mathrm{~kg} / \mathrm{s})$ and hence, the pressure of the RCS is constant.

Afterwards, the RCS continues losing inventory through the break and the pressure falls below 25 bar, leading to the discharge of ACCUs into the RCS (Fig. 3-a). After the depletion of the ACCUs, the residual power exceeds the power transmitted through to the SGs plus the one released through the break (Fig. 3-c). As a result, temperatures and pressures build up in the RCS, hindering steam condensation in the primary side of the U-tubes.

The lower mass flow rate through the loop A than through the loop B leads to an earlier dry-out of the SGA primary side (at about $6.50 \mathrm{~h}$ ) compared to SGB (at about $7.50 \mathrm{~h}$ ). After dry-out, the void fraction in the cold leg entrance of the corresponding loop jumps to 0.25 and remains constant in this value, because the steam coming from the core is blocking the water flow through the break. Later on, at $8.50 \mathrm{~h}$, the cold legs reach saturation, leading first to a sudden increase of the void fraction (Fig. 4-b-c). Despite the renewed condensation in the SGs due to the generated steam (Fig. 4-b), it is not sufficient to compensate the loss of inventory and hence, core uncovery occurs shortly afterwards.

As a result, core temperatures increase first due to the decay heat and then, at about $9.50 \mathrm{~h}$, due to the oxidation of the Zircaloy claddings. In the absence of AM measures, the SA continues its progression with the detection of a CET above $650{ }^{\circ} \mathrm{C}$, the release of $\mathrm{U}$ $\mathrm{Zr}-\mathrm{O}$ mixtures to the core region, their relocation to the lower plenum in different steps (few tons at $10 \mathrm{~h}$ after SCRAM; 20 additional tons of corium in the following $30 \mathrm{~min}$ ) and the eventual failure of the RPV at about $11.50 \mathrm{~h}$.

The predicted evolution of the accident is consistent with the results obtained for a similar SBLOCA sequence by GRS using MELCOR (Sonnenkalb, 2001). In ASTEC simulations the intervention of the EFWS and the availability of 3 out of 4 HPIS trains are considered, while in the MELCOR simulations they are not. Despite these different hypotheses, a qualitative comparison can be made. Although the HPIS stops earlier the injection in ASTEC, the cooling effect of the EFWS on the primary circuit is able to delay core melting with respect to the MELCOR calculation. Therefore, vessel failure occurs later (at about $11.50 \mathrm{~h}$ ) than in the referred work (at about $9.75 \mathrm{~h}$ ). Further details about this comparison can be found in (Gómez-García-Toraño, 2017).

\subsection{Reference SBLOCA sequence with SBO at different times}

The previous section has shown that the postulated SBLOCA with unlimited AC power leads to RPV failure in a time window of $12 \mathrm{~h}$. Within this chapter, it is assumed that the plant experiences a SBO at $1 \mathrm{~h}$ or $6 \mathrm{~h}$ after SCRAM during Ref-SBLOCA. The sequences are identified with $A C 1 h$ and $A C 6 h$, which involve all the plant active safety systems (see Section 2.2) up to the of $A C$ power supply. For better readability, Fig. 5 shows a sketch of the primary loop containing the pressurizer and the associated secondary loop together with the safety systems involved after the SBO i.e. accumulators.

The computed evolution of the system pressure, the core liquid level (relative to the bottom of the core active height) and the SGB liquid level (relative to the bottom of the riser) is shown in Fig. 6.

For $A C 1 h$, the EFWS does not manage to inject water into the SGs, since the set point is not reached (see Section 2.2). As a result, the secondary side of the SGs is not able to cool down the primary side, which is maintained at high pressures until the reactor is much voided. For this case, the accident progresses quickly, leading to RPV failure at high pressures. Conversely, the accident is slowed down if SBO occurs after the refilling of one SG e.g. AC6h. In such case, as soon as the injection of EFWS is stopped, the heat transfer from the primary to the secondary circuit is deteriorated. Therefore, there is a lower condensation in the primary side of the SGs and hence, a faster increase of the RCS pressure than in the reference case. All things considered, an additional grace time of up to $6 \mathrm{~h}$ for AM measures may be achieved if the secondary side of the SGs is completely refilled in case the plant meets a situation of SBO.

\section{Analysis of SBLOCA-sequences with SAM}

The previous chapter has shown that, if no AM is considered, the selected SBLOCA sequences lead to RPV failure at medium pressures. The aim now is to put in place SAM measures in order to prevent or, if not possible, to mitigate the accident. Considering an intact containment, the SAM procedures of a German Konvoi PWR foresee a Primary Side Depressurization (PSD) as a first SAM measure (Braun et al., 2014). After the reactor is depressurized, the most imperative SAM measure is core reflooding. Within this section, the following roadmap has been followed:

Firstly, the impact of a delayed PSD on the severe accident progression is investigated both for a late and early SBO in Section 4.1. The delay is relative to the fulfilment of the PBF criterion i.e. detection of a CET $=400{ }^{\circ} \mathrm{C}$. Afterwards, the Section 4.2 investigates the 

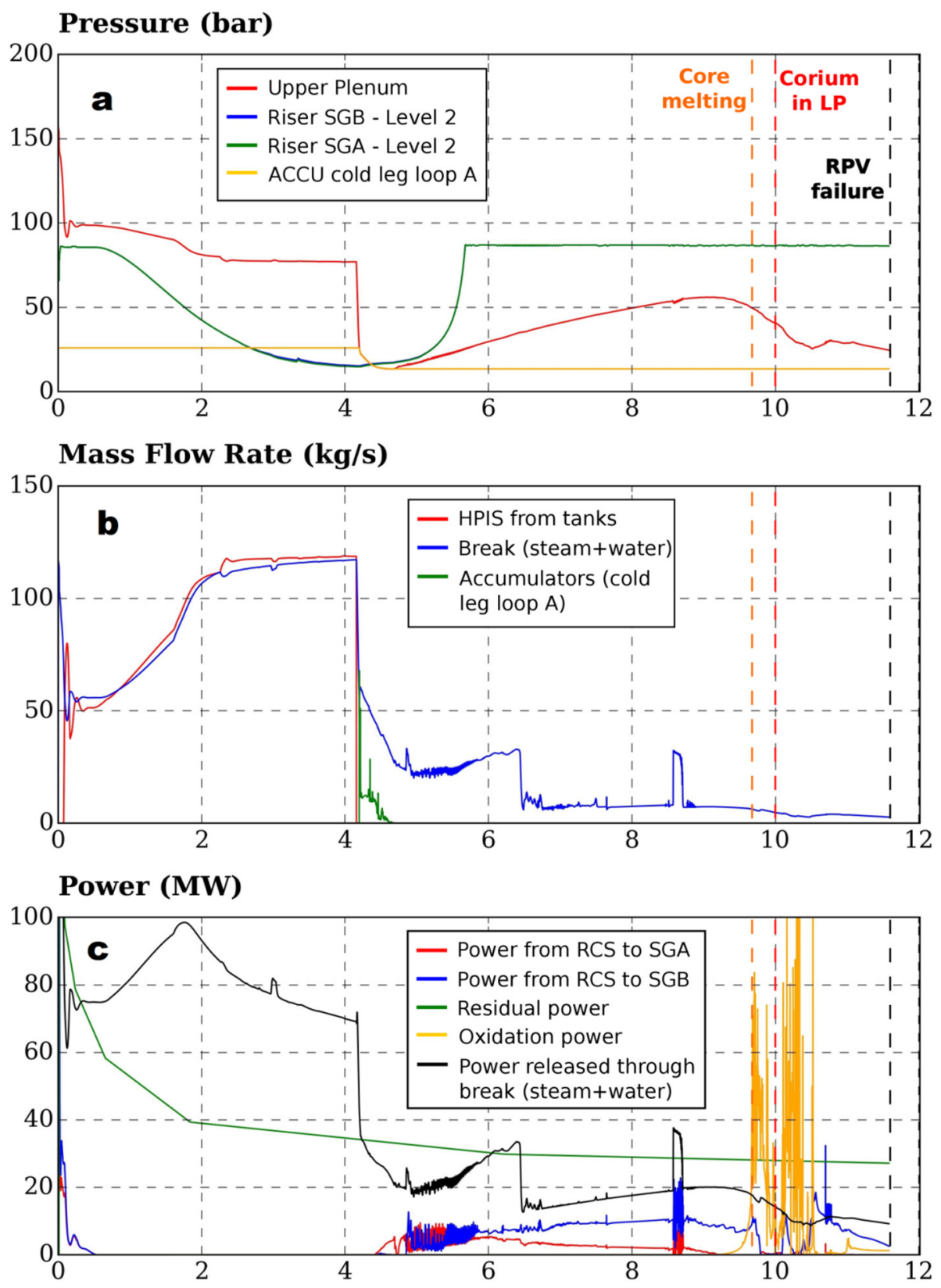

\section{$\Delta t$ after SCRAM (h)}

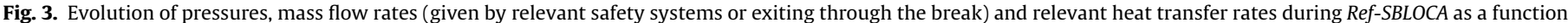
of the time after SCRAM. Major events of the simulation are represented by dashed vertical line.

impact of core reflooding considering that PSD occurs at $\mathrm{CET}=400^{\circ} \mathrm{C}$ by means of all pressurizer valves. Therein, a combined analysis of the reflooding delay (relative to PSD onset i.e. CET $400{ }^{\circ} \mathrm{C}$ ), the used mobile pump and the SBO time is investigated. A flow chart summarizing all performed SBLOCA calculations is shown in Fig. 7.

\subsection{Primary side depressurization and passive core reflooding}

Within this section, the sequences $A C 1 h$ and $A C 6 h$ have been considered. In a Konvoi PWR, PSD is generally executed as soon as the CET exceeds $400{ }^{\circ} \mathrm{C}$ or when the core liquid level falls below min3 (Roth-Seefrid et al., 1994). However, this work considers that the measurement of the liquid level is not available, which implies that the earliest initiation of PSD is the detection of CET $400{ }^{\circ} \mathrm{C}$. Besides, it is considered that PSD may be delayed $0-80$ min with respect to such detection due to harsh environmental conditions experienced by the plant crew.

\subsubsection{Loss of $A C$ power at $6 \mathrm{~h}$}

Firstly of all, the impact of a delayed PSD on the sequence AC6h is investigated. For that aim, the grace times gained due to PSD (with respect to the sequence $A C 6 h$ ) are represented in Fig. 8 as a function of the PSD delay (relative to the detection of CET $400{ }^{\circ} \mathrm{C}$ ). The graph contains several black dashed vertical lines, which are the occurrence times of main events of the sequence without any PSD i.e. AC6h. 


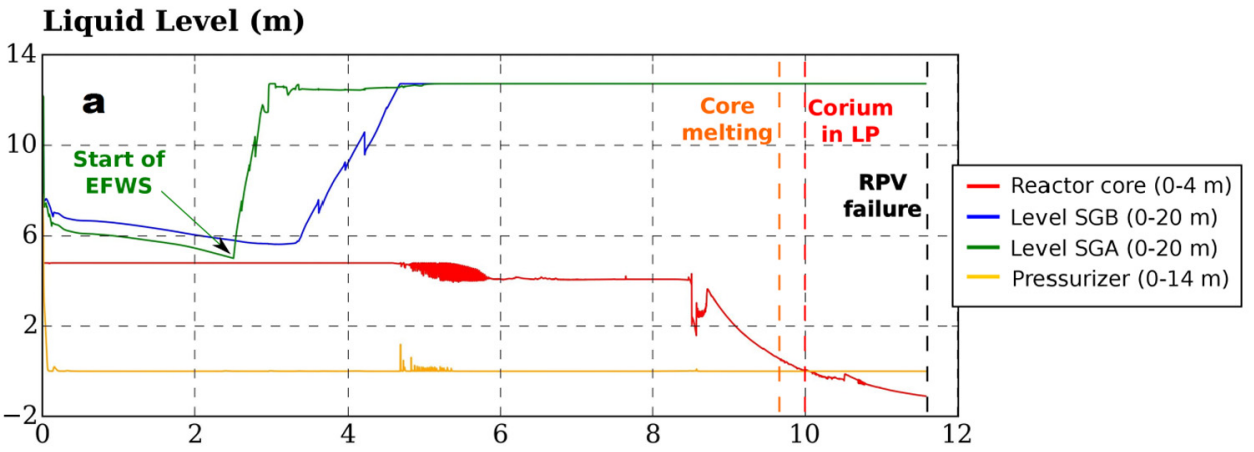

Void (-)

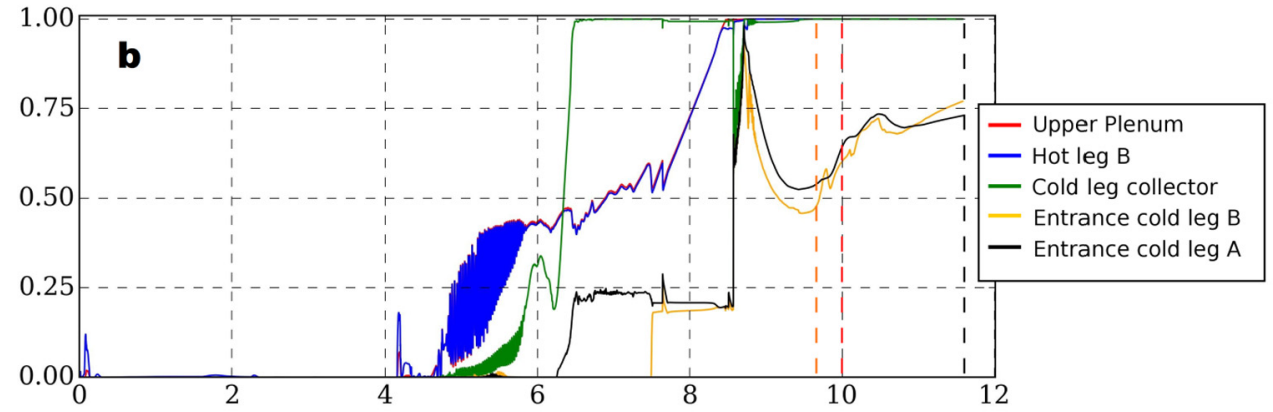

Temperature (K)

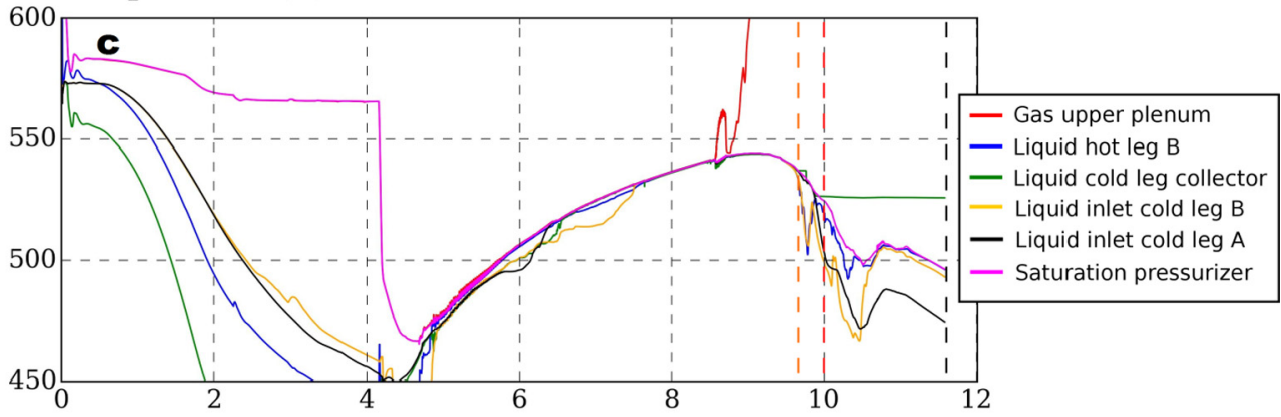

$\Delta t$ after SCRAM (h)

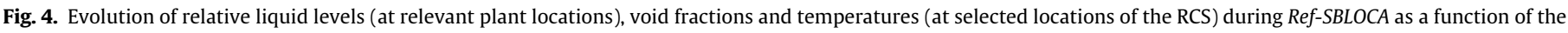
time after SCRAM. Major events of the simulation are represented by dashed vertical lines.

Table 2

Summary of events during the sequence Ref-SBLOCA (SBLOCA with unlimited AC power supply) relative to the break opening.

\begin{tabular}{ll}
\hline Time $(\mathrm{h})$ & Name of Event \\
\hline 0.00 & Break opening \\
0.01 & SCRAM (Containment overpressure of $30 \mathrm{mbar})$ \\
& - Feed water loop A/B closed \\
& ECCS Admission turbine A/B closed \\
0.03 & - Activation Extra Borating System $2.30 \mathrm{~m}):$ \\
& - Coast-down MCP loop A, B \\
& - Failure of $100 \mathrm{~K} / \mathrm{h}$ cooldown through SGs \\
& - Activation trains HPI_A1, HPI_A2, HPI_A3 \\
& Deactivation Extra Borating System (tanks empty) \\
& EFWS injecting into SGB (Liquid level SGB $<4.5$ m) \\
2.26 & Deactivation of HPI_A1/2/3 (tanks empty): \\
4.18 & - Failure of sump recirculation mode \\
4.20 & Accumulator discharge into cold/hot legs \\
9.20 & Detection of CET $400{ }^{\circ} \mathrm{C}$ \\
9.62 & Detection of CET $650{ }^{\circ} \mathrm{C}$ \\
9.67 & First cladding dissolution by molten Zircaloy \\
9.98 & First material slump into the lower plenum \\
10.30 & 20 corium tons in the lower plenum \\
11.50 & Lower head vessel failure
\end{tabular}

For example, let us consider that a 40-min delayed PSD is carried out aiming at delaying the progression of $A C 6 h$. At the moment of PSD initiation, the core has already started melting (indicated by the last vertical line). In addition, the action would anticipate the corium relocation to the lower plenum $(-0.20 \mathrm{~h})$, delay a 20-toncorium relocation to the lower plenum $(+3 \mathrm{~h})$ and delay RPV failure $(+3.7 \mathrm{~h})$ with respect to $A C 6 h$.

Additionally, Fig. 9 illustrates the influence of a delayed PSD on the RCS pressure and the temperature of the metallic layer in the lower plenum (LP) as a function of the time after the detection of CET $400^{\circ} \mathrm{C}$. Therein, red crosses mark PSD initiation (for the sequences with PSD) and black points mark the occurrence of RPV failure.

Results show that PSD does not delay significantly core melting nor the corium relocation to the lower plenum, but it extends at least $1.30 \mathrm{~h}$ the time to RPV failure if performed within the first 40 min after detecting CET $400^{\circ} \mathrm{C}$ (see Fig. 8). In fact, a 40-min delayed PSD provides the longest grace times to prevent the relocation of 20 corium tons to the lower plenum ( $+3 \mathrm{~h})$ and RPV failure $(+3.7 \mathrm{~h})$.

This behaviour occurs because the accumulators manage to cool down the metallic layer in the lower plenum (Fig. 9). As a result, the heat transfer from the metallic layer to the vessel wall 


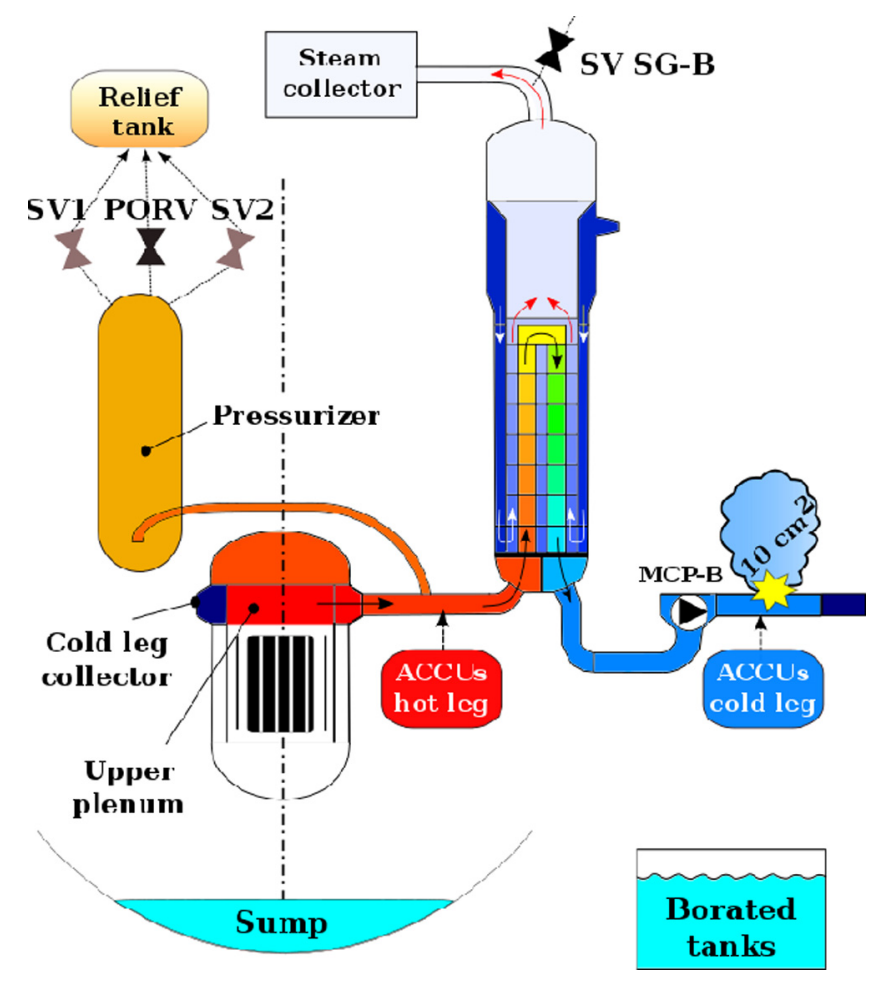

Fig. 5. Sketch of the primary loop containing the pressurizer and its associated secondary loop, together with the plant safety systems involved in AC1h-AC6h. No active systems work after loss of AC power supply.

decreases and the wall heats up slowly. The cooldown continues until the accumulators become empty and additional tons of corium tons relocate to the $L P$, which leads to the heat up of the metallic layer until vessel failure. It should be stated that the validity of the last finding is limited, since the reality shows that the corium may still relocate to the LP even if the molten pool is surrounded by water (Broughton et al., 1989; Seiler and Tourniaire, 2014).

\subsubsection{Influence of the SBO time}

The attention is now focused on the effect of SBO time on PSD performance. For that aim, another set of calculations with different PSD delays has been simulated based on $A C 1 h$. The grace times gained due to PSD are illustrated in Fig. 10 as a function of the delay since the conditions for PSD were fulfilled. The comparison between Figs. 8 and 10 yields the following results:

- The grace times to avoid core melting, relocation to LP and RPV failure are extended if PSD is initiated at CET $400{ }^{\circ} \mathrm{C}$. However, the extension is more significant in $A C 1 h_{P S D C E T 400 C}(\sim 1.7 \mathrm{~h}$, $1.8 \mathrm{~h}, 3.7 \mathrm{~h}$ ) than in $A C 6 h_{\text {PSDCET4OOC }}(\sim 0.2 \mathrm{~h}, 0.4 \mathrm{~h}, 1.3 \mathrm{~h})$. This is motivated by the higher mass flow rate injected by the ACCUs in the first case (see higher core liquid level in Fig. 11), which is related to their higher discharge pressure upon PSD initiation ( 25 bar vs 12 bar). In turn, this happens because the ACCUs were already involved in previous stages of the accident in AC6 $h$ (Fig. 3-a-b). Grace times are also extended for PSDs with 20 min delay, but less significantly than for the sequences without delay.

- The maximum PSD delay in order to significantly postpone the time of RPV failure is 40 min since the detection of CET $400{ }^{\circ} \mathrm{C}$. In fact, although corium relocation in the LP has already occurred in this case, PSD manages to extend about $4.5 \mathrm{~h}$
$\left(A C 1 h_{P S D 40} \min\right.$ vs $\left.A C 1 h\right)$ and $3.70 \mathrm{~h}\left(A C 1 h_{P S D 40 \text { min }}\right.$ vs $\left.A C 6 h\right)$ the time to RPV failure. Reasons behind this delay were explained in Section 4.1.1.

- PSD does not delay RPV failure if it is initiated $1 \mathrm{~h}$ after the detection of CET $400^{\circ} \mathrm{C}$, because more than 20 tons have been heating up the lower head wall for at least 20 min. However, it brings the benefit of avoiding RPV failure at high pressures.

Summing up, the performance of PSD without delay allows an extension of the grace time to prevent core melting and RPV failure. The delays are higher for AC1h than for AC6h due to the higher inventory of the ACCUs. However, the global grace time to prevent RPV failure is still higher in $A C 6 h_{P S D 400 C}(5.90 \mathrm{~h}+6.00 \mathrm{~h}=11.90 \mathrm{~h}$ vs. $10.60 \mathrm{~h}$ of $A C 6 h)$ than in $A C 1 h_{P S D 400 C}(7.25 \mathrm{~h}+1.00 \mathrm{~h}=8.25 \mathrm{~h}$ vs $4.60 \mathrm{~h}$ of $A C 1 h)$.

\subsubsection{Comparison with other studies and discussion}

The calculations presented above suggest the existence of a time window within which the action significantly delays core melting and RPV failure. In particular, PSD should be initiated at the stipulated time (i.e. when CET exceeds $400^{\circ} \mathrm{C}$ ), or, if not possible, during the following $20 \mathrm{~min}$ after such detection. This value is congruent with that contained in the SAMGs of the Konvoi PWR for very small breaks (Braun et al., 2014; Loeffler et al., 2012). In addition, the previous calculations have predicted that the longest time window to RPV failure takes place for a 40-min delayed PSD. However, it is difficult to extrapolate this finding to the reactor, because the plant crew will not be likely to wait for $40 \mathrm{~min}$ under such stressful conditions, but to immediately execute it to provide coolability and prevent RPV failure at medium-high pressures.

\subsection{Primary side depressurization and active core reflooding}

Once the RCS has been depressurized through a PSD, the subsequent SAM measure is the injection of water into the RCS. The current section investigates the impact of core reflooding on the sequences $A C 1 h_{P S D C E T 400}$ and $A C 6 h_{\text {PSDCET40o (which assume a suc- }}$ cessful PSD at CET $400{ }^{\circ} \mathrm{C}$ ). For both sequences, injection occurs at different times by means of the mobile pumps (see flow chart in Fig. 7). Calculations are terminated when one of the following three conditions is fulfilled: core liquid level higher than min3 ( $15 \mathrm{~cm}$ above core active head), final time of the simulation reached (i.e. $10 \mathrm{~h}$ after reflooding onset) and RPV failure.

A detailed analysis on reflooding is performed in the first place for the sequence $A C 6 h_{P S D C E T 400}$. Afterwards, the influence of an early loss of AC power supply $\left(A C 1 h_{P S D C E T 400}\right)$ is compared to a late one in terms of core reflooding success.

\subsubsection{Loss of AC power at $6 \mathrm{~h}$ and PSD at CET $400^{\circ} \mathrm{C}$}

The study is divided in three parts: individual influence of mobile equipment (fixed pump), individual influence of reflooding time (fixed injection time) and combined influence of reflooding time and mobile equipment.

4.2.1.1. Influence of mobile equipment. At first, the influence of different mobile equipment on the core liquid level and the corium mass in the core during a 40-min-delayed reflooding (relative to PSD initiation i.e. CET $400^{\circ} \mathrm{C}$ ) is studied. The evolution of such variables is depicted in Fig. 12 as a function of the time after PSD initiation, together with the case without active core reflooding $\left(A C 6 h_{P S D C E T 400}\right)$. The red line marks reflooding initiation (for the cases involving reflooding) whereas black points at the end of curves mark the occurrence of RPV failure.

The equipment $\mathrm{AE} 18 \mathrm{G}$ does not manage to inject water into the reactor, because its pressure head is always lower than the pressure in the RCS. Consequently, core uncovery evolves similarly to 


- Ref - AC1h - AC6h
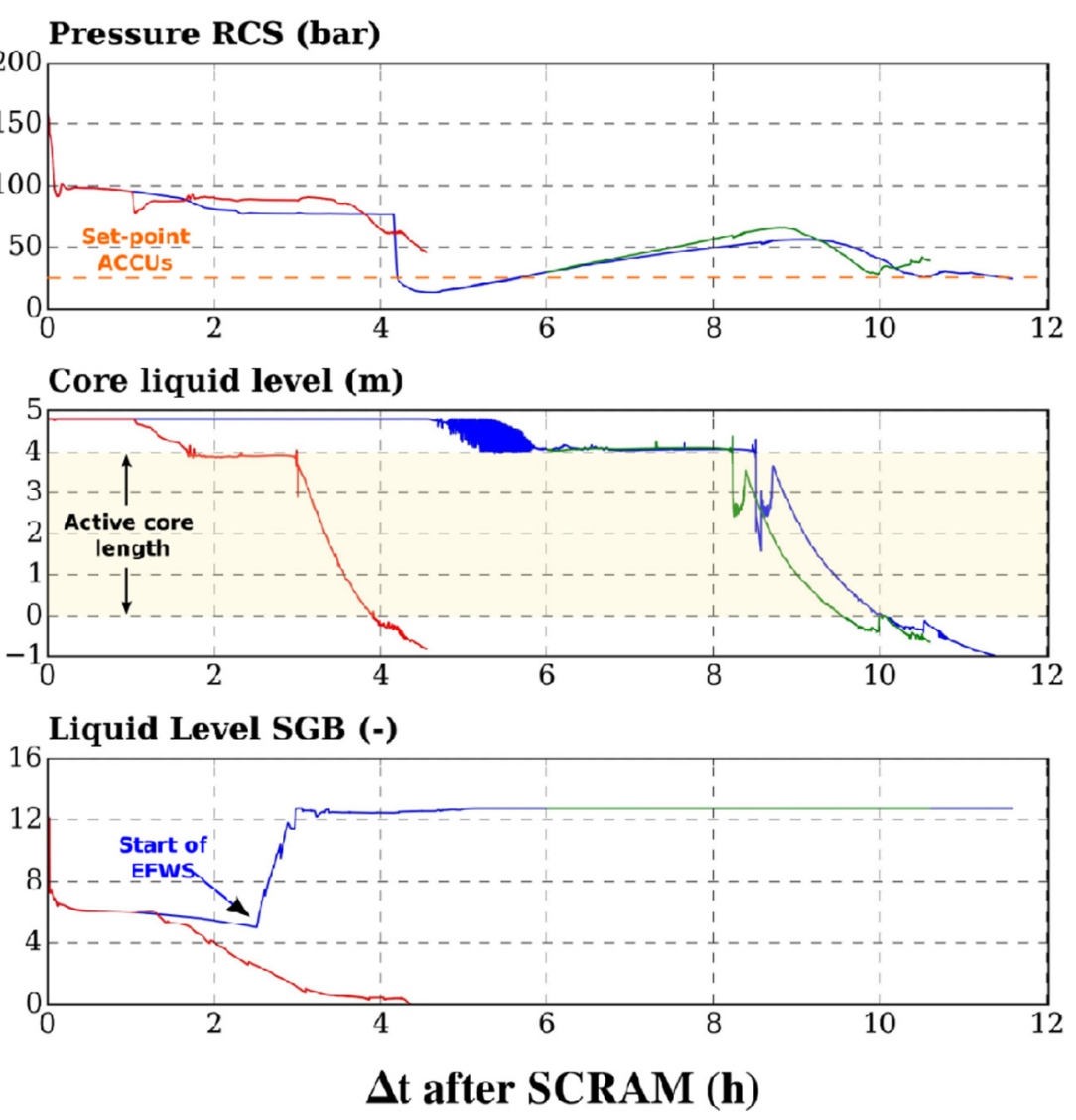

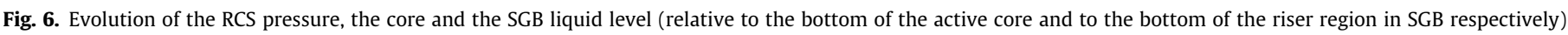
during SBLOCA sequences without (Ref) and with SBO ( $A C 1 h$ and $A C 6 h)$ as a function of the time after SCRAM.

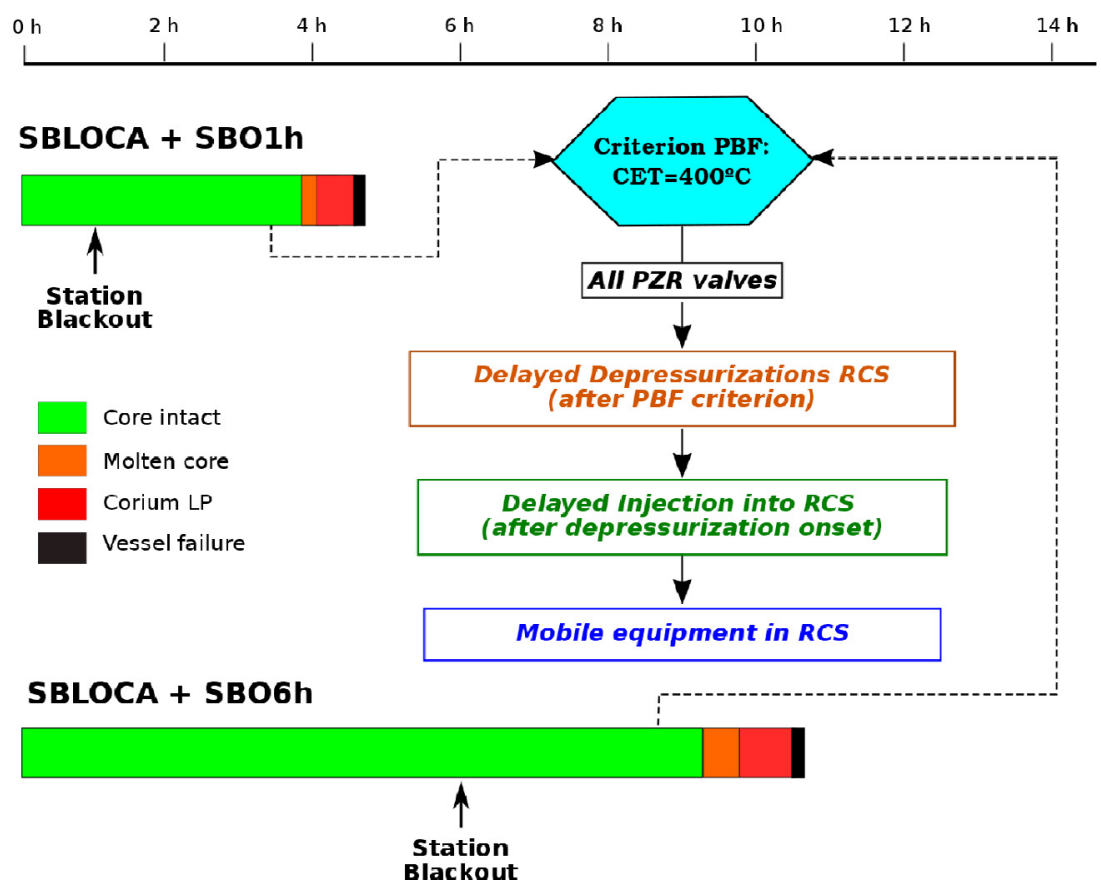

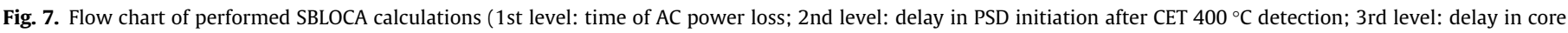
reflooding after PSD initiation, initiated at CET $400^{\circ} \mathrm{C}$; 4 th level: mobile pump used for core reflooding). 


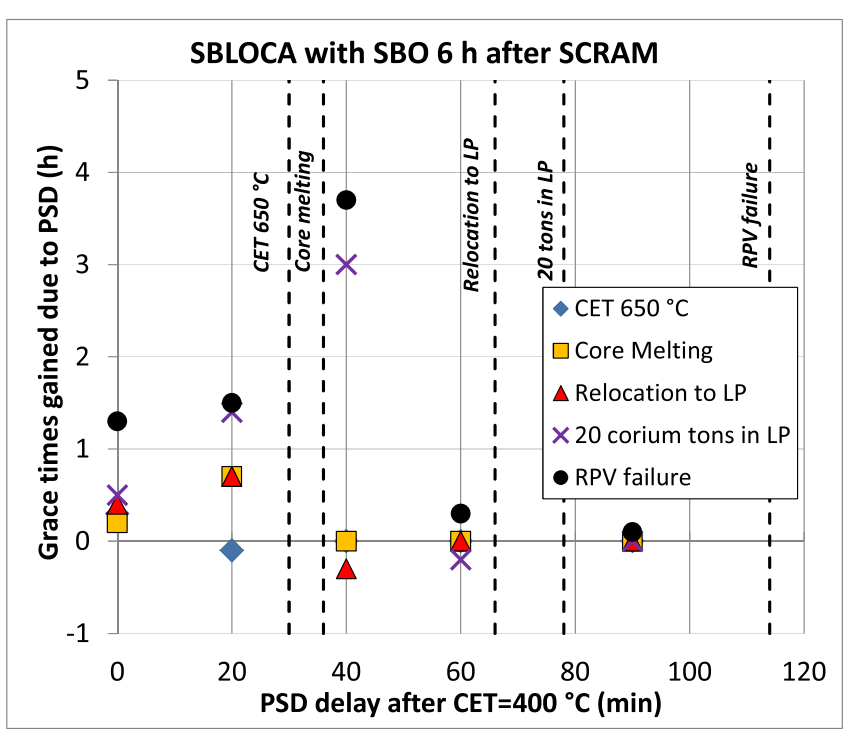

Fig. 8. Grace times gained due to PSD in comparison to the AC6h (SBLOCA with SBO $6 \mathrm{~h}$ after SCRAM without PSD) as a function of the delay after the detection of $\mathrm{CET}=400^{\circ} \mathrm{C}$. Black dashed vertical lines mark occurrence times of major events in AC6h.

$A C 6 h_{P S D C E T 400 C}$, the times being slightly different due to the additional venting paths opened in the RCS. A slight increase of the pump pressure head (e.g. HH125) results in a higher efficiency, but still low, because the RCS pressure oscillates around the pressure head of the pump. Therefore, the quench front progression is slow. Nevertheless, this is not translated into the further release of corium into the core. The influence of repressurization on the Reflooding Mass Flow Rate (RMFR) is overcome with increasing pressure heads and high mass flow rates (e.g. M651h), which allow a quick core refilling.

4.2.1.2. Influence of injection time. Turning now to the injection time, several delays on the deployment of the mobile pump M651h (see features in Table 1) have been simulated. The influence of this delay on the core liquid level and the corium mass in the core is shown in Fig. 13 as a function of the time after PSD initiation, together with the sequence without active reflooding
( $\left.A C 6 h_{P S D C E T 400 C}\right)$. In both graphs, red crosses indicate reflooding initiation (for the cases involving reflooding) whereas black points at the end of certain curves indicate RPV failure.

The calculations yield the following results:

A 40-min-delayed reflooding produces a temperature excursion, which leads to the release of several corium tons into the core region, but it can terminate the accident without major core damage. On the other hand, a 3-h-delayed injection can neither prevent nor delay vessel failure. This happens because at least 40 corium tons relocate from the core region to the lower plenum at about $1.80 \mathrm{~h}$ (see decline of the corium mass in core in Fig. 13) and heat-up the RPV wall for almost $1 \mathrm{~h}$, leading ultimately to RPV failure. In between, intermediate behaviours can be seen: a 2-h delayed reflooding already meets 30 corium tons in the core and 50 corium tons in the LP. In that case, core reflooding does not cause further degradation, but a bundle cool down. Regardless of the injection time, the generated pressure peaks do not affect the pump performance due to its high pressure head (50 bars).

Therefore, it can be concluded that core reflooding has to be initiated as early as possible in order to terminate the accident without any major damage. If that is not possible, reflooding encounters a severely degraded core, and may not prevent nor avoid RPV failure.

4.2.1.3. Influence of RMFR and injection time on selected Figures of Merit (FOM). After studying the individual impact of the injection time and the mobile equipment on the progression of $A C 6 h_{P S D C E T 400 c}$, this section addresses their combined influence on the final Core Damage State (Fig. 14-a), mass of corium in the core and in the LP (Fig. 14-b-c), relative time to RPV failure since PSD initiation (Fig. 14-d), mass of water injected into the reactor (Fig. 14-e) and refilling time (Fig. 14-f). The graphs can be read using the same methodology as the one detailed in (Gómez-Garcí a-Toraño et al., 2017), but they differ in two aspects: first, the abscissa represents the delay in core reflooding with respect to PSD initiation; second, the vertical lines represent the occurrence times of major events in the sequence without any active core reflooding i.e. $A C 6 h_{P S D C E T 400}$.

The following key points can be extracted if the analysis is restricted to the injection time and the RMFR without entering in details of the system pressure:
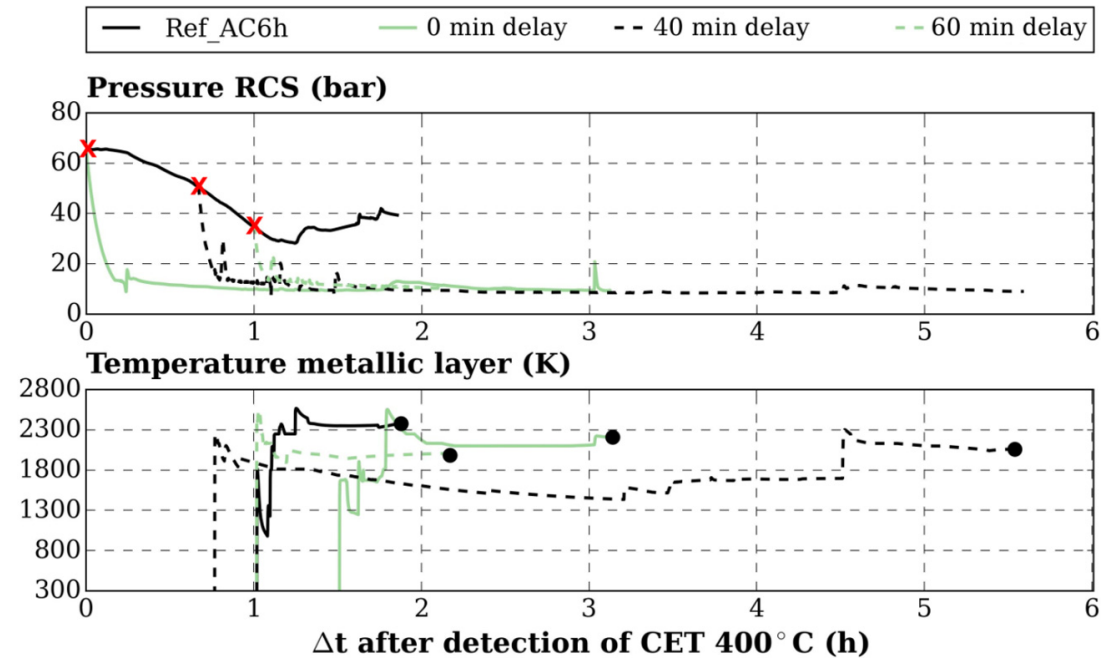

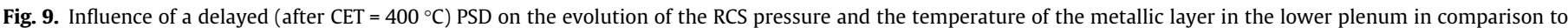

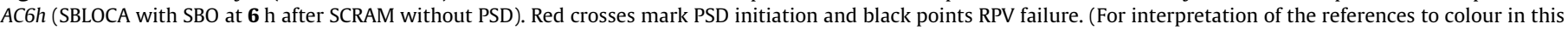
figure legend, the reader is referred to the web version of this article.) 


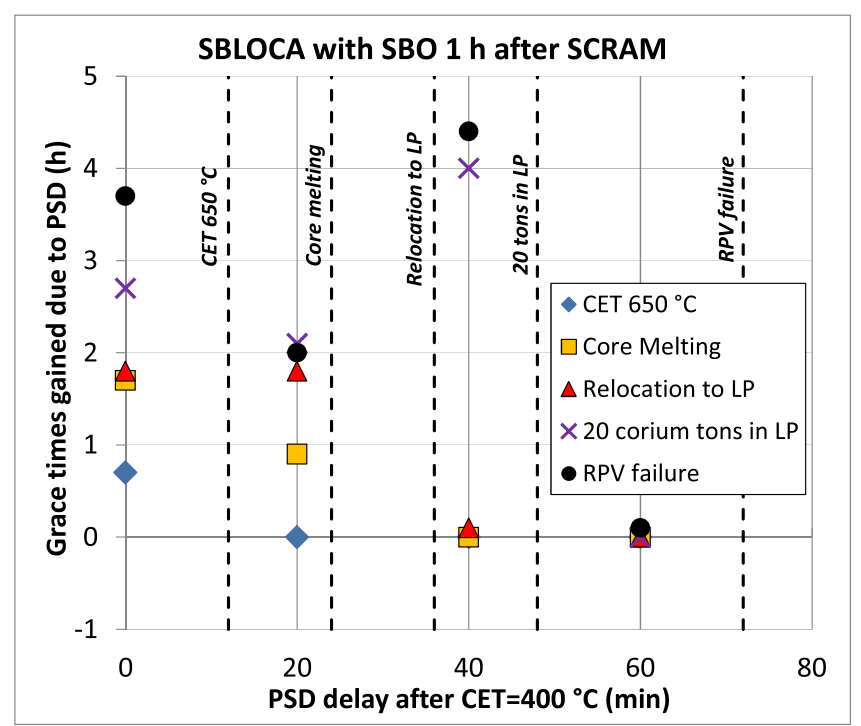

Fig. 10. Grace times gained due to PSD in comparison to the AC1h (SBLOCA with SBO $1 \mathrm{~h}$ after SCRAM without PSD) as a function of the delay after the detection of $\mathrm{CET}=400{ }^{\circ} \mathrm{C}$. Black dashed vertical lines mark occurrence times of major events in AC1h.

- Injections performed before detecting CET $650{ }^{\circ} \mathrm{C}$ (maximum delays of $\sim 40 \mathrm{~min}$ ) are able to refill the core in about $30 \mathrm{~min}-$ $1 \mathrm{~h}$ with localized burst of some claddings if RMFRs are higher than $40 \mathrm{~kg} / \mathrm{s}$ (Fig. 14-a-e). This demands the provision of less than 20 water tons (Fig. 14-f). If this is not possible, the release of $\mathrm{U}-\mathrm{Zr}-\mathrm{O}$ mixtures into the core region are limited to 20 corium tons if RMFRs are higher than $7.75 \mathrm{~kg} / \mathrm{s}$. However, for such cases, the refilling time is at least $30 \mathrm{~min}$ and the required water mass ranges from 50 to 300 tons (Fig. 14-a-e-f).

- Injections performed $1 \mathrm{~h}$ after the relocation of 20 tons of corium into the LP can neither prevent nor delay the failure of the RPV (Fig. 14-a-d). This is motivated by the fact that a large amount of corium (50 tons according to the decrease of corium mass in the core region in Fig. 13) has been heating up the top metallic layer (and hence, the RPV wall in contact with it), that water injection into the reactor cannot invert this tendency.

Concerning the rest of injections with a RMFR above $10 \mathrm{~kg} / \mathrm{s}$, it can be observed that the retention of a large amount of corium is predicted either in the core region or in the lower plenum (Fig. 14-b-c). However, these simulations entail uncertainty due to ASTEC V2.0 intrinsic limitations concerning degraded core reflooding (Chatelard et al., 2014) and the external simulation criteria (simulation finished when liquid level exceeds min3).

Up to this point, the combined influence of injection time and average RMFR injected in the RCS has been explained. However, the feedback of the system pressure on mobile system performance remains to be discussed. This dependency influences the ordinate of each point in the Fig. 14-a-f. This analysis is discussed in the following:

- The efficiency of low pressure pumps (AE18G and HH125) is very low even having initiated PSD at CET $400{ }^{\circ} \mathrm{C}$ because any water injection in the RCS yields a repressurization regardless of the injection time. Therefore, the RCS pressure rises above the pressure head of the equipment and the water supply is stopped. For example, the pump AE18G delivers a RMFR close to zero although its nominal RMFR is $130 \mathrm{~kg} / \mathrm{s}$ ( $0 \%$ efficiency). Similarly, the pump HH125 delivers $8 \mathrm{~kg} / \mathrm{s}$ although it can potentially deliver $45 \mathrm{~kg} / \mathrm{s}$ (20\% efficiency).

- High pressure pumps (M651h and M100h) are highly efficient at any injection time even if the RCS becomes repressurized, because the created pressure peaks are well below their pressure head ( 45 and 50 bar).

- Medium pressure equipment such as the XH100 provide, as anticipated, an intermediate performance. Although the RMFR injected by the pumps is lower than the nominal, the repressurization does not prevent the equipment from supplying a considerable RMFR (50-75\% efficiency).

In contrast to the high and low pressure pumps, the injection time plays an important role for the medium pressure pumps, especially when the core starts to heat-up (between $0.50 \mathrm{~h}$ and $1.00 \mathrm{~h}$ ) and when a considerable amount of corium is released into the core (between $1.50 \mathrm{~h}$ and $2.00 \mathrm{~h}$ ). This happens because there is a high steam production that causes enhanced core oxidation and global temperature increase, which affects the pump performance. Once a considerable quantity of corium has relocated into the LP, the RMFR provided by such system becomes higher, since the quench front progresses in the core region in the absence of active material.

\subsubsection{Influence of the SBO time}

The same procedure has been repeated for the sequence $A C 1 h_{\text {PSDCET4OOC, }}$ the independent variables and the FOMs being identical to the previous calculations, as can be observed in Fig. 15. For this case, the injection is restricted to times beyond $1.20 \mathrm{~h}$ after

\section{- AC1h_PSD400 - AC6h_PSD400}

\section{Core liquid level (m)}

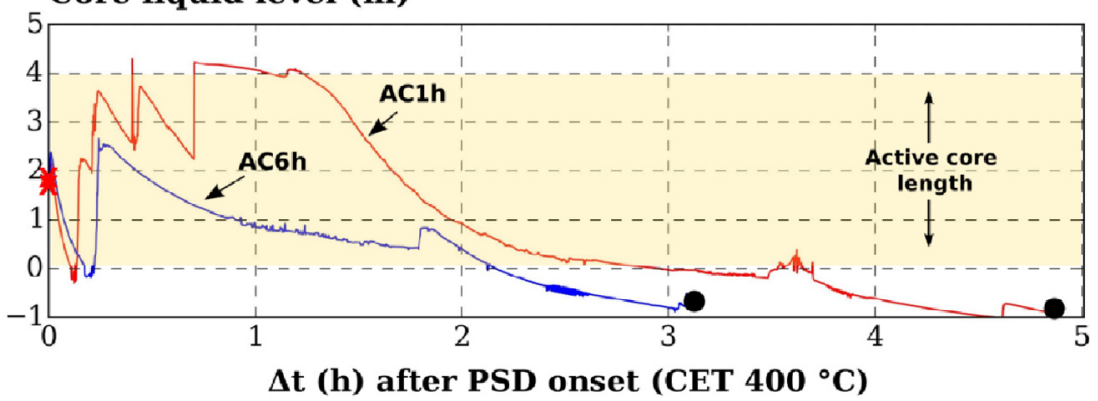

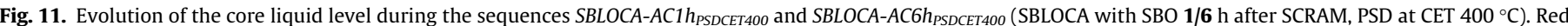

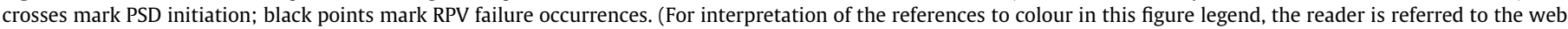
version of this article.) 


\begin{tabular}{llll|}
- & AC6h_PSDCET400 & -- & HH125: $50 \mathrm{~kg} / \mathrm{s}, 10 \mathrm{bar}$ \\
- & M651h: $22 \mathrm{~kg} / \mathrm{s}, 50 \mathrm{bar}$ & -- & AE18G: $130 \mathrm{~kg} / \mathrm{s}, 7 \mathrm{bar}$
\end{tabular}
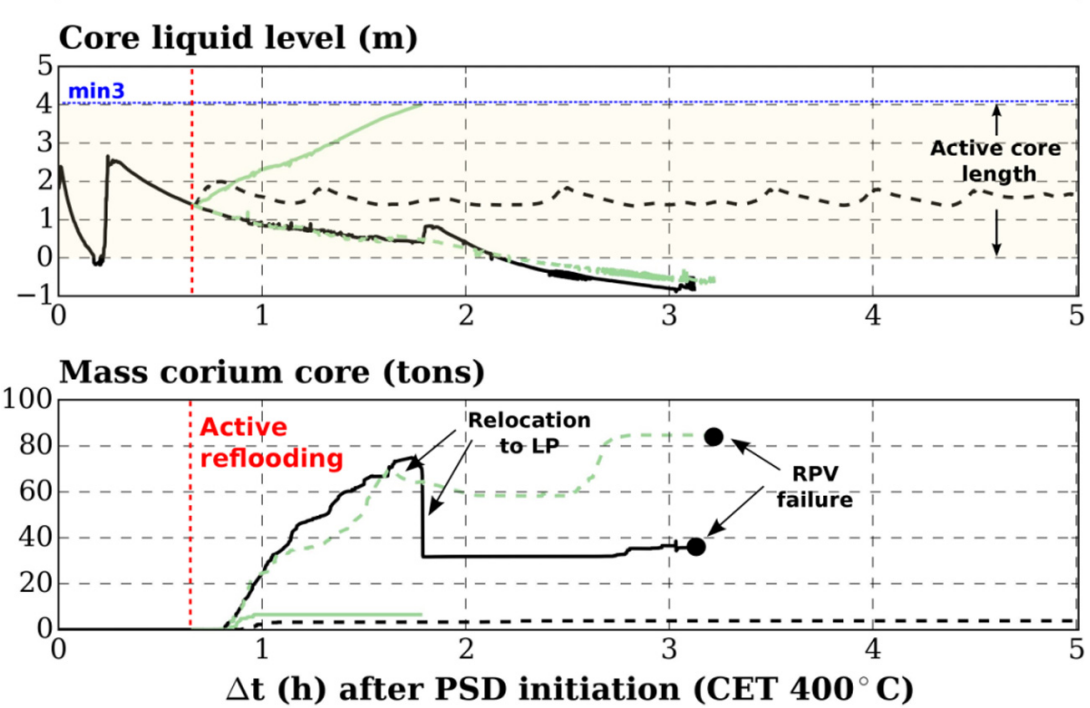

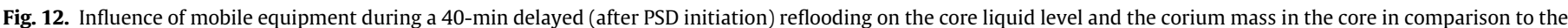

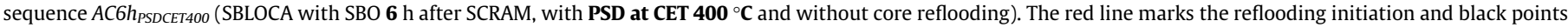
mark RPV failure. (For interpretation of the references to colour in this figure legend, the reader is referred to the web version of this article.)

\begin{tabular}{|llll|}
\hline & AC6h_PSDCET400 & --- & 2-h delayed reflood \\
- & 40-min delayed reflood & --- & 3 -h delayed reflood \\
\hline
\end{tabular}
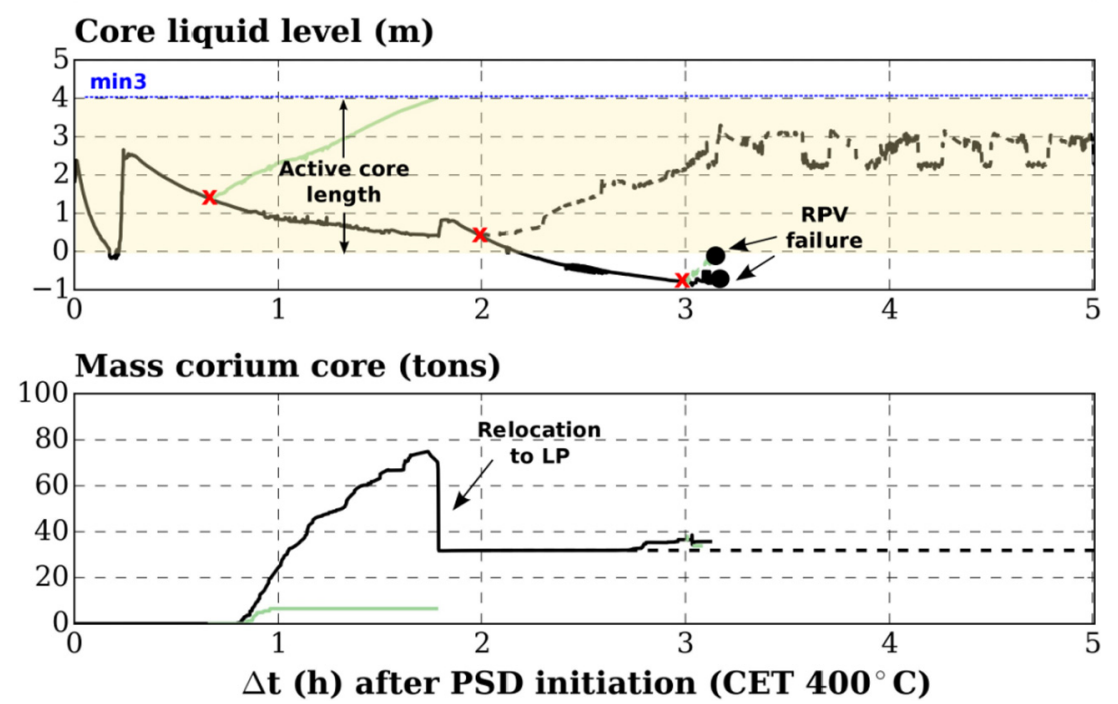

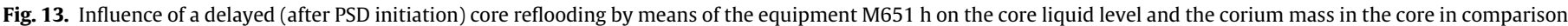

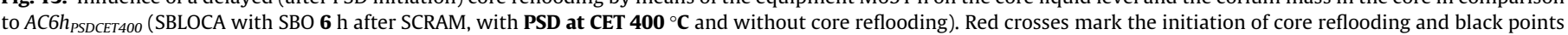
RPV failure.

PSD initiation, because the core is covered up to this time (see Section 4.1.2). The influence of the SBO time can be derived by comparing these graphs with the ones shown in Fig. 14. The results are compared to those obtained for $A C 6 h_{\text {PSDCET40oc: }}$ :

- Once the PSD is initiated, the grace time to prevent core melting is higher in $A C 1 h_{\text {PSDCET400C }}$ than in $A C 6 h_{\text {PSDCET400C }}$ ( $2 \mathrm{~h} \mathrm{vs} 20 \mathrm{~min}$ ). This occurs because the ACCUs inject enough water into the RCS to completely cover the core in $A C 1 h_{P S D C E T 400 C}$, but not in $A C 6 h_{P S D C E T 400 C}$, where they cannot push the core liquid level above $2 \mathrm{~m}$ (half of the active length of the core) (see Fig. 11).
- The minimum RMFR to mitigate the accident without major damage is higher in $A C 1 h_{P S D C E T 400 C}$ than in $A C 6 h_{P S D C E T 400 C}$ (20 kg/s vs.7.75 kg/s), because the residual power is higher at CET $650{ }^{\circ} \mathrm{C}$ ( $32 \mathrm{MW}$ vs $28.5 \mathrm{MW}$ ). To put the times in an absolute scale, a CET of $650{ }^{\circ} \mathrm{C}$ was detected at a time of $1.0 \mathrm{~h}$ (since PSD initiation) $+2.5 \mathrm{~h}$ (between loss of $\mathrm{AC}$ and PSD) $+1.0 \mathrm{~h}$ (between SCRAM and loss of AC) $\sim 5 \mathrm{~h}$ since SCRAM in

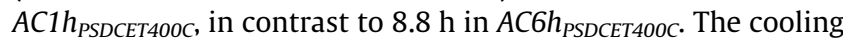
effect of the secondary also additionally contributes to the reduction of the minimum RMFR in the case of $A C 6 h_{\text {PSDCET4OOC, }}$ but it is very limited, since non-condensable gases start to be produced above CET $650^{\circ} \mathrm{C}$. 
M Mhilh: 50 har, $22 \mathrm{~kg} / \mathrm{s} \quad \nabla$ Mlouh: 45 har, $40 \mathrm{~kg} / \mathrm{s} \quad \Longleftrightarrow x H 100: 18 \mathrm{har}, 80 \mathrm{~kg} / \mathrm{s}$ is HH125: $10 \mathrm{bar}, 50 \mathrm{~kg} / \mathrm{s} \quad \square$ AE18G: $7 \mathrm{bar}, 130 \mathrm{~kg} / \mathrm{s}$

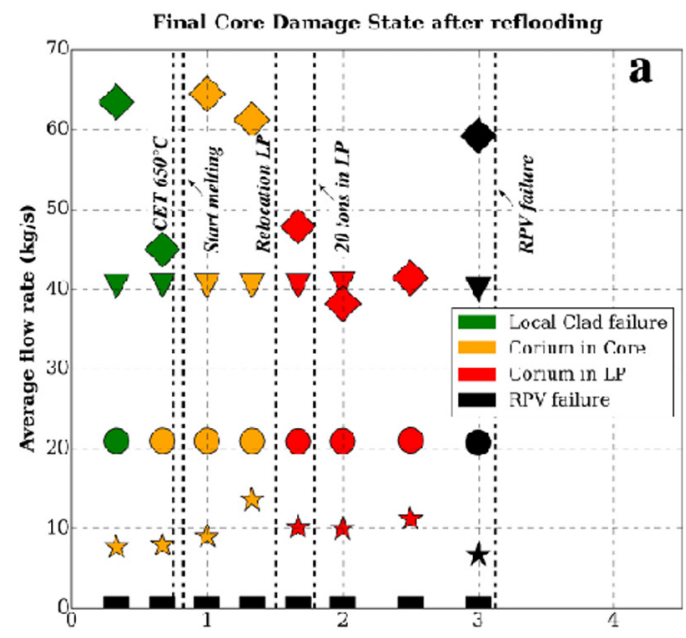

Injextion time (h) in $\Delta$ t. after PSD initiation (CET $400^{\circ} \mathrm{C}$ )

Final Mass of Corium relocated to LP

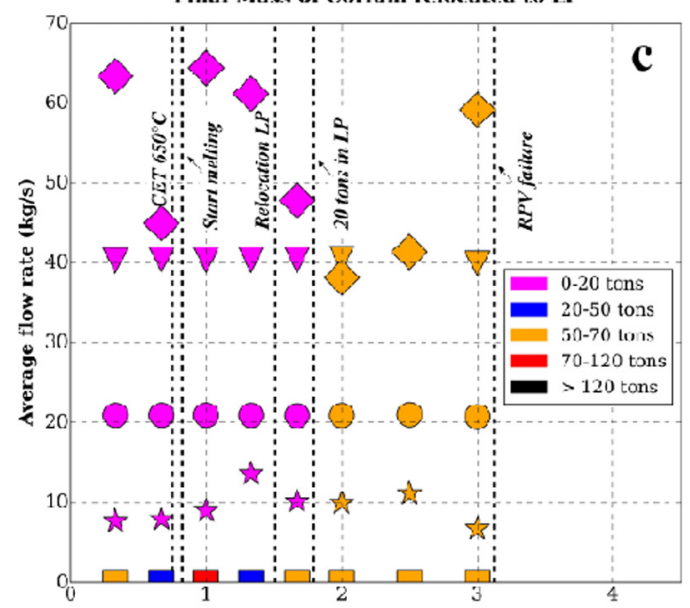

Injertion time (h) in At after PSD initiation (C.FT $400^{\circ} \mathrm{C}$ )

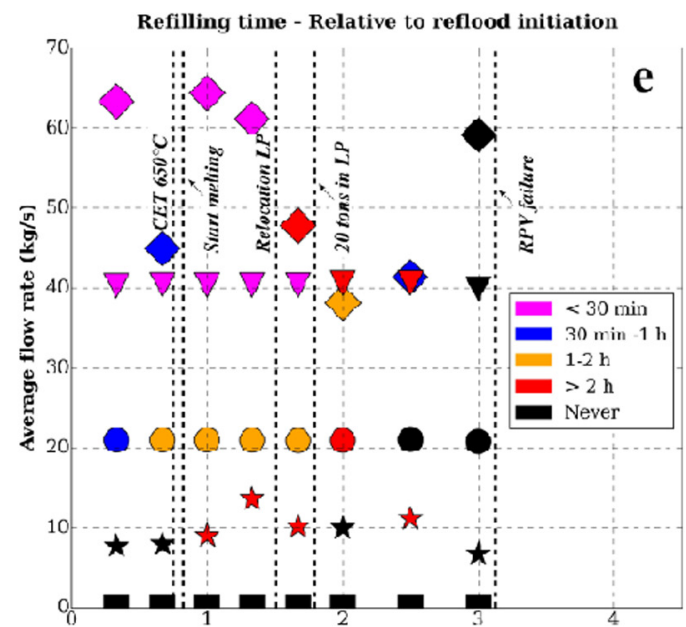

Injection time (h) in $\Delta t$ after PSD initiation (CET $400^{\circ} \mathrm{C}$ )

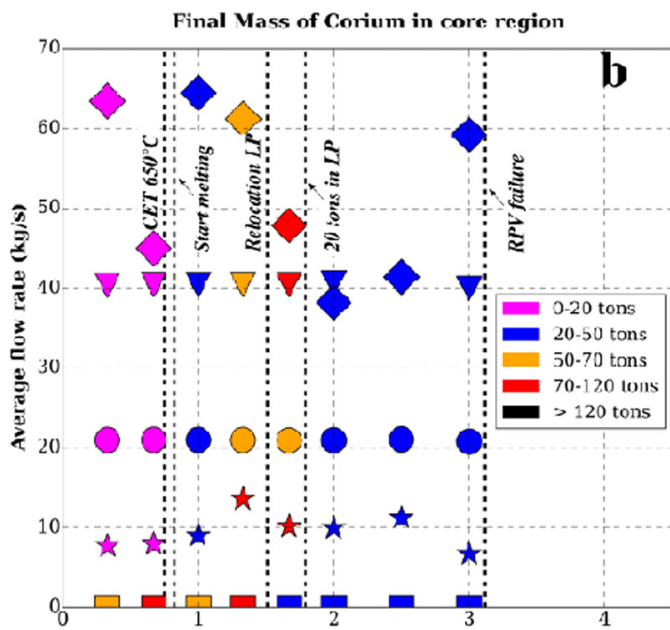

Injection time (h) in $\triangle$ t. after PSD initiation (CET $400^{\circ} \mathrm{C}$ )

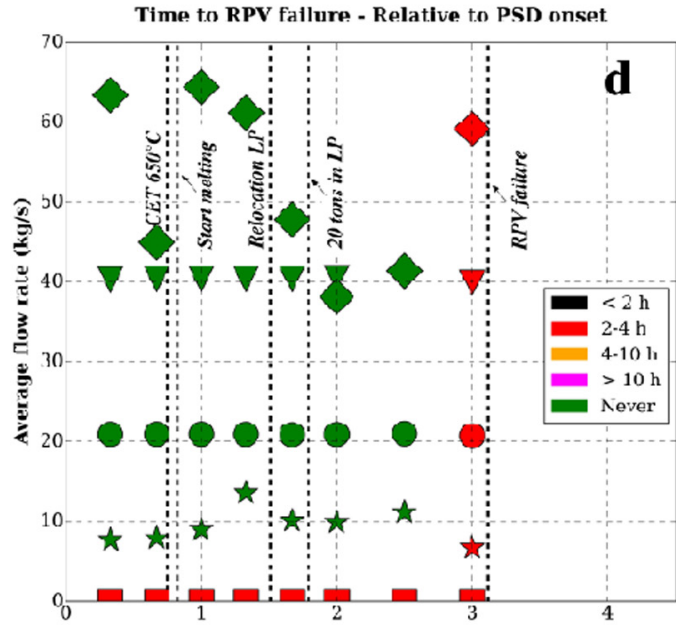

Injertion time (h) in $\wedge$ t after PSD initiation (CFT $400^{\circ} \mathrm{C}$ )

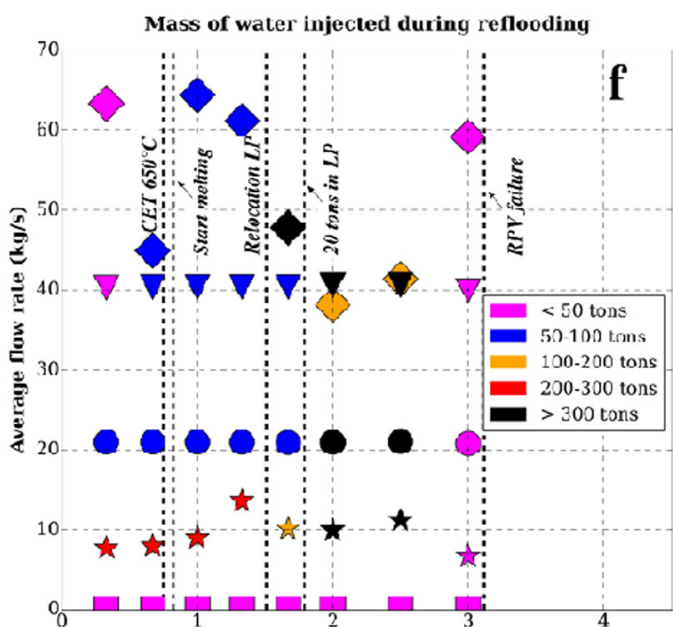

Injection time (h) in $\Delta t$ after PSD initiation (CET $400^{\circ} \mathrm{C}$ )

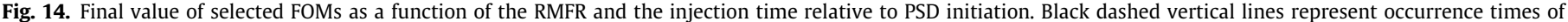
major events in $A C 6 h_{P S D C E T 400}$ (SBLOCA with SBO at $\mathbf{6}$ h after SCRAM, with PSD at CET $400{ }^{\circ} \mathrm{C}$ and without reflooding). 

O M65̄1h: $50 \mathrm{har}, 22 \mathrm{~kg} / \mathrm{s} \quad \nabla$ M100h: $45 \mathrm{har}, 40 \mathrm{~kg} / \mathrm{s} \quad \bigotimes$ XH100: $18 \mathrm{har}, 80 \mathrm{~kg} / \mathrm{s}$ is HH12J: $10 \mathrm{bar} ; 50 \mathrm{~kg} / \mathrm{s} \quad \square$ AE18G: $7 \mathrm{bar} ; 130 \mathrm{~kg} / \mathrm{s}$

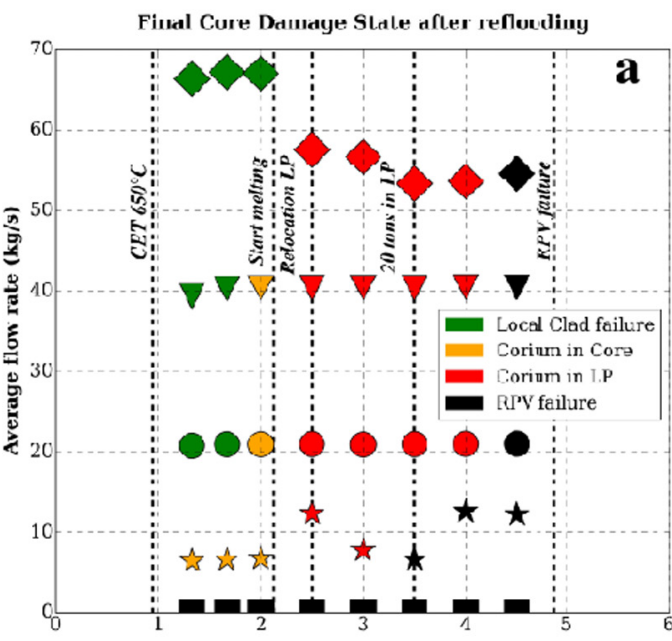

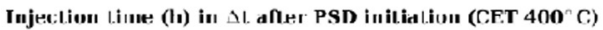

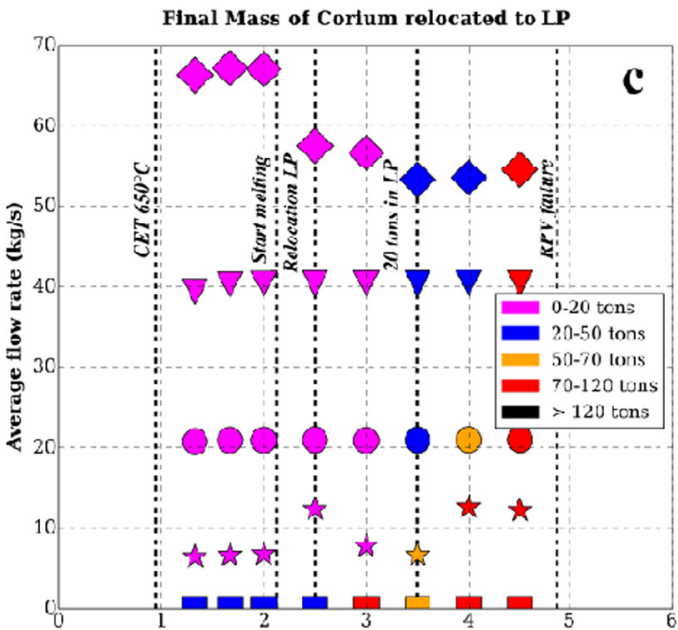

Injection time (h) in $\Delta t$ after PSD inftiation (CET $400^{\circ} \mathrm{C}$ )

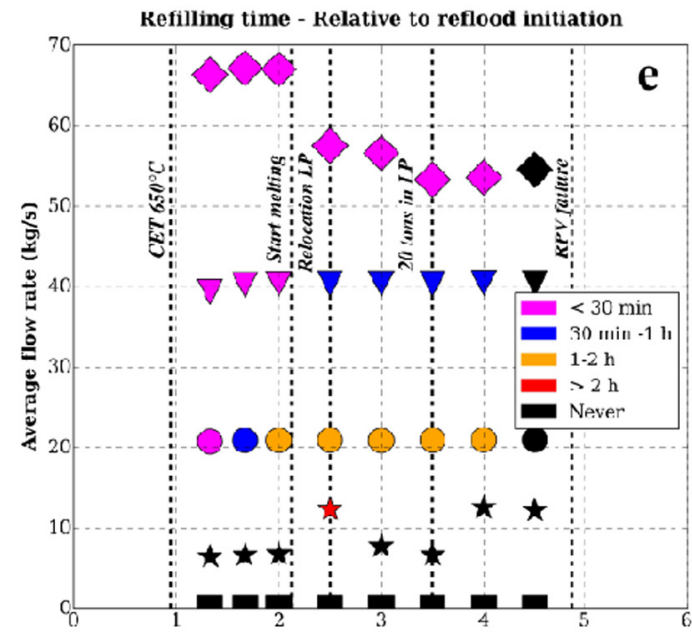

Injection time (h) in $\Delta t$ after PSD initiation (CET $400^{\circ} \mathrm{C}$ )

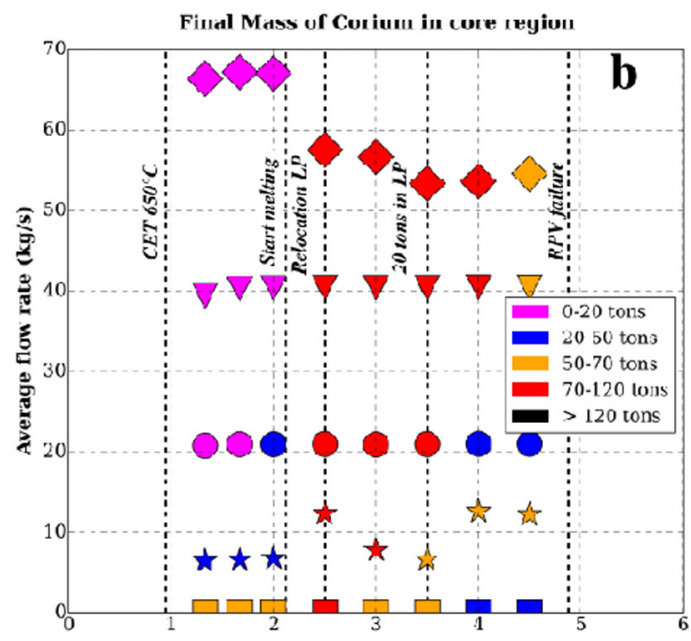

Injection lime (h) ill $\triangle \mathrm{l}$ afler PSD inilialion (CET 400'C)

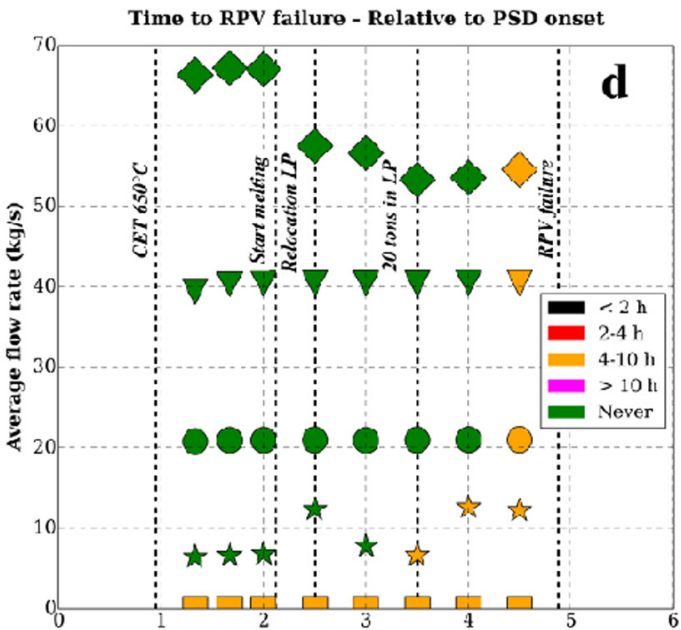

Injection time (h) in $\triangle t$ after PSD initiation (CET $\left.400^{\circ} \mathrm{C}\right)$

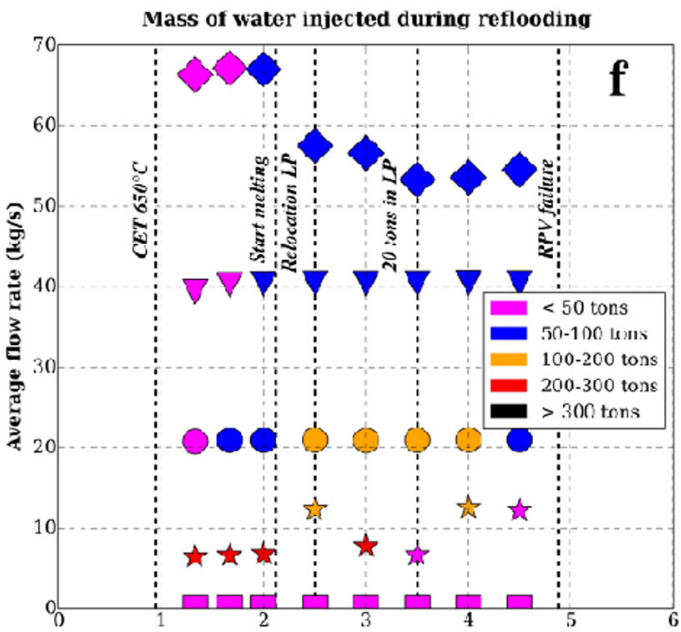

Injection time (h) in $\triangle t$ after PSD initiation (CET $400^{\circ}$ )

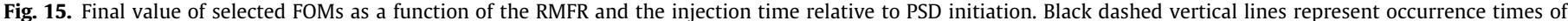
major events in $A C 1 h_{P S D C E T 400}$ (SBLOCA with SBO at $\mathbf{1} \mathrm{h}$ after SCRAM, with PSD at CET $400{ }^{\circ} \mathrm{C}$ and without reflooding). 


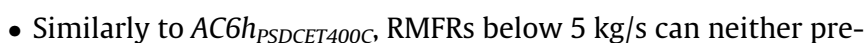
vent nor delay the RPV failure, because they cannot compensate the ongoing loss of inventory. Likewise, injections performed $1 \mathrm{~h}$ after the relocation of 20 corium tons in the LP do not influence vessel failure regardless of the RMFR injected. Corium retention from this moment on is predicted due to the external simulation criteria (simulation terminated $10 \mathrm{~h}$ after reflooding onset).

- The performance of the mobile equipment is comparable to that explained for a late loss of AC power supply in the sense that low and high pressure pumps have a poor/excellent performance, and medium pressure equipment has an intermediate one. However, differently to the previous chapter, the medium pressure equipment has a better performance at any time (60-80\% nominal flow rate) than in $A C 6 h_{\text {PSDCET400C. }}$

\subsubsection{Comparison with other studies and discussion}

The previous section has predicted the existence of a minimum RMFR of about 7.75-20 kg/s to mitigate the accident without major damage (less than 20 corium tons in core) if injection is performed near the detection of CET $650{ }^{\circ} \mathrm{C}$. These values are in agreement with the $300 \mathrm{gpm}(\sim 20 \mathrm{~kg} / \mathrm{s})$ recommended for Westinghouse type PWRs (NEI, 2006), and with the $5.80-12.50 \mathrm{~kg} / \mathrm{s}$ predicted by AREVA using MELCOR for German Konvoi PWRs (Braun et al., 2014). The deviation comes from the fact that AREVA presents an interpolated diagram with different regions, whereas this work provides point data. Interpolating ASTEC values, the minimum RMFR would be $4.50-13.50 \mathrm{~kg} / \mathrm{s}$, which is similar to the aforementioned study. Further details about this comparison can be found in (Gómez-García-Toraño, 2017).

If mobile systems were used to provide this flow rate, an interesting conclusion can be drawn. First of all, the tanks containing the water should have a capacity of about $50-100 \mathrm{~m}^{3}$. Then, considering that PSD is performed at CET $400{ }^{\circ} \mathrm{C}$, Table 2 and Fig. 8 provide the existence of the following time windows relative to the loss of AC:

- About $2 \mathrm{~h}$ up to CET $400^{\circ} \mathrm{C}$ i.e. initiation of primary bleed and passive feed.

- About $3 \mathrm{~h}$ up to CET $650{ }^{\circ} \mathrm{C}$ i.e. close to core melting.

- About $4 \mathrm{~h}$ up to corium relocation to the lower plenum.

- About 5 h to RPV failure.

Practical exercises in an American three-loop Westinghouse PWR have estimated that the time window between the mobile pump deployment order and the injection into the RCS is about $2 \mathrm{~h}$ (USNRC, 2012). Extrapolating a similar measure for the Konvoi PWR, this means that the deployment order of a high pressure pump should be issued with a maximum delay of $\mathbf{1 ~ h}$ after the entrance in SBO so that the pump can inject before the CET exceeds $650{ }^{\circ} \mathrm{C}$.

Although the injection by means of mobile equipment was discussed in Germany in the light of Fukushima (BMUB, 2012), such measure has been recently ruled out (BMUB, 2016). Reasons behind this decision lie in the hazard of a radionuclide release to the environment if the connection to the primary is not successfully performed. In the absence of an external injection, the other path to provide core coolability would be the restoration of key plant safety systems by means of mobile DGs. Considering that the operators succeeded in restoring the AC before the CET exceeds $650^{\circ} \mathrm{C}$, it would be possible to derive the potential efficiency of the retrieved core cooling systems. However, the influence of a potential RCS repressurization has to be considered.

The retrieval of one train of the HPIS $(75 \mathrm{~kg} / \mathrm{s})$ or two trains of the Control Volume Chemical System $(24 \mathrm{~kg} / \mathrm{s})$ would immediately cool down the bundle, since their efficiency is not affected by a potential repressurization of the reactor. The recovery of one train of the LPIS would have a low performance (as the rest of low pressure equipment analysed in this work), but it would be higher than the $20 \%$ obtained with the pump HH125 due to the higher pressure head. Considering an efficiency of $20 \%$ for one train of the LPIS, this means $30 \mathrm{~kg} / \mathrm{s}$ per train. Therefore, the recovery of one train of the LPIS should also cool down the core. Finally, the recovery of the Extra Borating System may mitigate the accident without major damage for a late SBO, but would not avoid RPV failure for an early one.

The methodology followed to assess the success of core reflooding extends the scope of the computational aids related to this topic in German Konvoi PWRs (Braun et al., 2014). First of all, the analyses are extended to injection times beyond CET $=650^{\circ} \mathrm{C}$, whereas the aforementioned study assumes that reflooding always occurs at $\mathrm{CET}=650^{\circ} \mathrm{C}$. Furthermore, this study characterizes the final state of the reactor with several FOMs (e.g. core damage state, mass of corium in core, etc.) instead of one (success/failure reflooding). The approach is similar to the one used to derive the experimental reflooding map (Hering et al., 2015). However, the parameters influencing the success/failure of core reflooding are similar to the ones used in the plant (Braun et al., 2014): the injection time (instead of the core damage state at reflooding) and the real mass flow rate injected by each system (instead of the nominal flow rate). Therefore, the influence of the system pressure is implicitly considered, which allows the plant crew to anticipate the potential efficiency of each system.

\section{Conclusions}

Within this work, the severe accident code ASTEC V2.0 has been used for the improvement of several in-vessel SAM measures (e.g. primary side depressurization, core reflooding) in a generic German Konvoi PWR based on SBLOCA sequences.

First of all, several SBLOCA sequences in the cold leg of the pressurizer loop with an additional SBO have been simulated. Results show that core melting and vessel failure can be considerably delayed if the SGs are filled before the plant is struck by SBO.

Based on these sequences, an extensive and systematic assessment of primary side depressurization and core reflooding has been carried out, providing the following main results:

- Primary Side Depressurization should be performed when the CET $>400{ }^{\circ} \mathrm{C}$ or, if not possible, with a maximum delay of 20 min since that instant in order to significantly delay core melting and vessel failure. A 1-h delayed depressurization does not influence the time to vessel failure, but should be executed in any case to avoid vessel failure at medium pressures.

- Core reflooding should be launched shortly after the CET exceeds $650{ }^{\circ} \mathrm{C}$ with at least $7.50-20 \mathrm{~kg} / \mathrm{s}$ in order to mitigate the accident without major core damage. This flow rate mainly depends on when the plant is struck by SBO. Moreover, calculations show that vessel integrity cannot be preserved by means of reflooding if more than 20 corium tons are present in the lower plenum for more than $20 \mathrm{~min}$.

- Although the possibility of mobile pumps injecting into the RCS has been temporarily discarded, this work suggests that, in case of an external injection, the deployment order of medium-high pressure mobile equipment should be done within $1 \mathrm{~h}$ after the plant is struck by the SBO. The mobile equipment should have a pressure head above 20 bars and provide the aforementioned mass flow rate. Moreover, the potential water tanks should have a capacity of 50-100 water tons. If mobile equipment is not contemplated, diesel generators should be deployed aiming at restoring high-pressure core cooling systems. 
It is worth noting that the obtained results are strictly valid within the validation domain of ASTEC V2.0 (Chatelard et al., 2014). Therefore, the results concerning degraded core reflooding should be verified with the ASTEC V2.1 (Chatelard et al., 2016), which includes a new 2-D treatment of the thermal-hydraulics in the RPV However, the next step will be focused on the further improvement of SAM measures based on a total Station Blackout, which is the sequence with the highest significance for the overall risk of the German Konvoi PWR.

\section{Acknowledgements}

The authors would like to thank GRS for preparing the Konvoi input deck, and the necessary documentation for its understanding. In addition, the authors would like to thank Javier Jiménez (KIT) and the ASTEC team in IRSN Cadarache (especially Laurent Laborde and Sebastien Belon) for the continuous support. The authors would like to acknowledge Martin Sonnenkalb and Nils Reinke (GRS), Florian Fichot (IRSN), Wolfgang Hering (KIT), Michael Buck (USTUTT) and Matthias Braun (AREVA) for fruitful discussions. Finally, the authors would like to thank the financial support from the EU CESAM consortium and the NUSAFE research program of KIT.

\section{References}

BMUB, 2012. German Action Plan for the implementation of measures after the Fukushima Dai-ichi reactor accident.

BMUB, 2014. German Action Plan for the implementation of measures after the Fukushima Dai-ichi reactor accident.

BMUB, 2016. Fortgeschriebener Aktionsplan zur Umsetzung von Maßnahmen nach dem Reaktorunfall in Fukushima.

Braun, M., Löffler, M., Plank, H., Asse, D., Dimmelmeier, H., 2014. Severe Accident Management - Optimized Guidelines and Strategies, in: Proceedings of the 10th Conference on Nuclear Thermal Hydraulics, Operation and Safety (NUTHOS-10). 14th-18th December, Okinawa, Japan.

Broughton, J.M., Kuan, P., Petti, D.A., Tolman, E.L., 1989. A scenario of the three mile island unit 2 accident. Nucl. Technol. 87, 34-53.

Bunt, R., Corradini, M., Ellison, P., Farmer, M., Francis, M., Gabor, J., Gauntt, R., Henry, C., Linthicum, R., Luangdilok, W., Lutz, R., Paik, C., Plys, M., Rabiti, C., 2015. Reactor Safety Gap Evaluation of Accident Tolerant Components and Severe Accident Analysis. In: Proceedings of the 16th International Meeting on Nuclear Thermal-Hydraulics (NURETH-16). Chicago, USA, pp. 4661-4674.

Chatelard, P., Reinke, N., Arndt, S., Belon, S., Cantrel, L., Carenini, L., Chevalier-Jabet, K., Cousin, F., Eckel, J., Jacq, F., Marchetto, C., Mun, C., Piar, L., 2014. ASTEC V2 severe accident integral code main features, current V2.0 modelling status, perspectives. Nucl. Eng. Des. 272, 119-135. http://dx.doi.org/10.1016/j. nucengdes.2013.06.040.

Chatelard, P., Belon, S., Bosland, L., Carénini, L., Coindreau, O., Cousin, F., Marchetto, C., Nowack, H., Piar, L., Chailan, L., 2016. Main modelling features of the ASTEC V2.1 major version. Ann. Nucl. Energy 93, 83-93. http://dx.doi.org/10.1016/j. anucene.2015.12.026.

EPRI, 1993. Severe Accident Management Guidance Technical Basis Report, Volume 1: Candidate High-Level Actions and their Effects. TR-101869. Palo Alto, United States.

EPRI, 2012. Severe Accident Management Guidance Technical Basis Report (Vols. 1 and 2). Report 1025295. Palo Alto, United States.

European Commission, 2000. Concerted Action on Severe Accident Management Implementation and Expertise in the European Union (SAMIME), Contract No. FI4S-CT98-0052.

European Commission, 2017. FAST Nuclear Emergency Tools (FASTNET). [WWW Document]. <http://cordis.europa.eu/project/rcn/198668_en.html> (accessed 1.1.17).

Gómez-García-Toraño, I., 2017. Further development of Severe Accident Management Strategies for a German PWR Konvoi plant based on the European Severe Accident Code ASTEC (PhD Thesis). Fakultät für Maschinenbau, Karlsruhe Institute für Technologie, Karlsruhe, Germany.

Gómez-García-Toraño, I., Sanchez, V., Stieglitz, R., 2017. Investigation of SAM measures during selected MBLOCA sequences along with Station Blackout in a generic Konvoi PWR using ASTECV2.0. Ann. Nucl. Energy 105, 226-239. doi: 10.1016/j.anucene.2017.02.030.

GRS, 2002. Assessment of the Accidental Risk of Advanced Pressurized Water Reactors in Germany. GRS-184. Germany.

GRS, 2017. CESAM: Code for European Severe Accident Management. Available from: <http://www.cesam-fp7.eu/>

Hering, W., Homann, C., Stuckert, J., 2015. Integration of New Experiments into the Reflood Map. In: Proceedings of the 15th International Congress on Advances in Nuclear Power Plants (ICAPP-15). 3rd-6th May, Nice, France, pp. 1420-1428.

Hermsmeyer, S., Iglesias, R., Herranz, L.E., Reer, B., Sonnenkalb, M., Nowack, H. Stefanova, A., Raimond, E., Chatelard, P., Foucher, L., Barnak, M., Matejovic, P., Pascal, G., Vela Garcia, M., Sangoirgi, M., Pla, P., Grah, A., Strucic, M., Lajtha, G., Techy, Z., Lind, T., Koch, M., Gremme, F., Bujan, A., Sanchez, V., 2014. Review of current severe accident management (SAM) approaches for nuclear power plants in Europe requirements. JRC93082. doi:10.2790/38824.

IAEA, 2004. Implementation of Accident Management Programmes in Nuclear Power Plants - Safety Reports Series No. 32. Vienna, Austria.

IAEA, 2009. Severe Accident Management Programmes for Nuclear Power Plants. Safety Guide No. NS-G-2.15. Vienna, Austria.

Jacquemain, D., Vola, D., Meignen, R., Bonnet, J.M., Fichot, F., Raimond, E., Barrachin, M., 2015. Past and Future R \& D at IRSN on Corium Progression and Related Mitigation Strategies in a Severe Accident. In: Proceedings of the 16th International Meeting on Nuclear Thermal-Hydraulics (NURETH-16). Chicago, United States, pp. 7519-7537.

Klein-Heßling, W., Sonnenkalb, M., Jacquemain, D., Clément, B., Raimond, E., Dimmelmeier, H., Azarian, G., Ducros, G., Journeau, C., Herranz Puebla, L.E., Schumm, A., Miassoedov, A., Kljenak, I., Pascal, G., Bechta, S., Güntay, S., Koch, M. K., Ivanov, I., Auvinen, A., Lindholm, I., 2014. Conclusions on severe accident research priorities. Ann. Nucl. Energy 74, 4-11. http://dx.doi.org/10.1016/j. anucene.2014.07.015.

Loeffler, M., Braun, M., Plank, H., 2012. SAMGs II: Plant Specific Application, in: SARNET Course on Severe Accident Phenomenology and Management. KIT, Karlsruhe, Germany.

Ludwig, H., 2007. PWR Plant Design, in: ENEN Safety Course PWR Plant Design PWR Plant Design. Munich, Germany.

Lutz, R.J., Prior, R.P., 2016. Comparison of the Fukushima response in the United States and Europe. Paper No. 60101. In: Proceedings of the24th International Conference on Nuclear Engineering (ICONE-24). Charlotte, United States.

Miassoedov, A., Manara, D., Bottomley, D., Kiselova, M., Gmbh, A., 2015. Severe Accident Facilities for European Safety Targets: The SAFEST Project, in Proceedings of the 16th International Meeting on Nuclear Thermal-Hydraulics (NURETH-16). Chicago, United States, pp. 4604-4616.

NEA-OECD, 2013. The Fukushima Daiichi Nuclear Power Plant Accident: OECD/NEA Nuclear Safety Response and Lessons Learnt. NEA Report No. 7161. Paris, France.

NEI, 2006. B.5.b Phase 2 \& 3 Submittal Guideline. NEI 06-12. Walnut Creek, United States.

Nowack, H., Erdmann, W., Reinke, N., 2011. Application of ASTEC V2.0 to Severe Accident Analyses for German Konvoi Type Reactors, in: Proceedings of the 14th International Meeting on Nuclear Thermal-Hydraulics (NURETH-14). Toronto, Canada.

Reinke, N., Chan, H.-W., Sonnenkalb, M. 2013. Comparative Analysis of LOCA for German PWR with ASTEC and ATHLET-CD. In: Proceedings of the 44th Kerntechnik Jahrestagung, Berlin.

Roth-Seefrid, H., Feigel, A., Moser, H.J., 1994. Implementation of bleed and feed procedures in Siemens PWRs. Nucl. Eng. Des. 148, 133-150. http://dx.doi.org/ 10.1016/0029-5493(94)90105-8.

Seiler, J.M., Tourniaire, B., 2014. A phenomenological analysis of melt progression in the lower head of a pressurized water reactor. Nucl. Eng. Des. 268, 87-95. http://dx.doi.org/10.1016/j.nucengdes.2013.12.043.

Siemens, 1991. Der Druckwasserreaktor: Aufbau und Wirkungsweise der Gesamtanlage.

Sonnenkalb, M., 2001. Unfallanalysen für DWR vom Typ Konvoi (GKN-2) mit dem Integralcode MELCOR 1.8.4. GRS-A-2954. Germany.

USNRC, 2012. NUREG/CR-7110, Vol. 2. State-of-the-Art Reactor Consequence Analyses Project. Volume 2: Surry Integrated Analysis.

Van Dorsselaere, J.-P., Chatelard, P., Chevalier-Jabet, K., Nowack, H., Herranz, L.E. Pascal, G., Sánchez-Espinoza, V., 2015. ASTEC code development, validation and applications for severe accident management within the CESAM European project. In: Proceedings of the International Congress on Advances in Nuclear Power Plants. 3rd-6th May, Nice, France, pp. 1562-1570.

WENRA, 2007. WENRA Safety Reference Levels for Existing Reactors.

WENRA, 2014. WENRA Safety Reference Levels for Existing Reactors Safety Reference Levels for Existing Reactors. Update in relation to the lessons learned from TEPCO Fukushima Daiichi Accident.

Ziegler, A., Allelein, H.J., 2013. Reaktortechnik. Physikalisch-technische Grundlagen. Kapitel 10 - Moderne Leichtwasserreaktoren. Springer Vieweg. doi:10.1007| 978-3-642-33846-5. 